\title{
Life cycle, population structure and vertical distribution of Metridia spp. (Copepoda: Calanoida) in the Oyashio region (NW Pacific Ocean)
}

\author{
Gadi Padmavati $^{1,2}$, Tsutomu Ikeda ${ }^{1, *}$, Atsushi Yamaguchi ${ }^{1}$ \\ ${ }^{1}$ Marine Biodiversity Laboratory, Graduate School of Fisheries Sciences, Hokkaido University, 3-1-1 Minato-machi, \\ Hakodate, Hokkaido 041-0821, Japan \\ ${ }^{2}$ Present address: Ocean Science and Technology Cell, Department of Marine Living Resources, Andhra University, \\ Visakhapatnam - 530003, India
}

\begin{abstract}
Vertical distribution and population structure of Metridia pacifica and M. okhotensis were investigated at Site $\mathrm{H}$ in the Oyashio region (western subarctic Pacific) to evaluate their life cycle modes. Although recruitment of $M$. pacifica continued throughout the year in the top $250 \mathrm{~m}$ of the water column, 2 pronounced generations were recognized. The first generation was characterized by rapid development during the spring phytoplankton bloom (generation length: 2-3 mo), and the second by slow development (generation length: 9-10 mo) with overwintering at Stage 5 in deeper-layers (up to 1000-2000 m). In contrast, M. okhotensis was consistently found at depth (250-1000 m) throughout the year, except for excursions to the subsurface layer for spawning during the phytoplankton bloom. Developmental sequences of $M$. okhotensis could not be resolved very clearly, largely because of extremely low abundance of Copepodite Stages 2 and 3 (C2-C3). As a tentative life cycle scenario, the $\mathrm{C} 1$ produced during one year was considered to overwinter and develop to C5 through the phytoplankton bloom of the next year. These C5 overwinter and molt to C6 and reproduce during the phytoplankton bloom of the following year. Thus, the generation length of $M$. okhotensis is estimated as 2 yr. For both species, active spawning and subsequent growth are closely associated with phytoplankton bloom. For overwintering stages of both species, a large deposition of lipid in the body and its gradual decrease toward the onset of phytoplankton bloom of the next year was seen. While no comparable life cycle data is presently available for $M$. okhotensis, the present results of $M$. pacifica are compared with the results from other regions, showing a large betweenregion variation in the life cycle patterns of this species. Further, the present results are discussed in the context of broad overwintering mechanisms of pelagic copepods living in high-latitude seas.
\end{abstract}

KEY WORDS: Metridia pacifica $\cdot$ Metridia okhotensis $\cdot$ Vertical distribution $\cdot$ Life cycle $\cdot$ Oyashio Western North Pacific

Resale or republication not permitted without written consent of the publisher

\section{INTRODUCTION}

Throughout the subarctic Pacific, the zooplankton fauna is characterized by the predominance of a few large grazing copepods, such as Neocalanus cristatus, N. plumchrus, N. flemingeri and Eucalanus bungii (Mackas \& Tsuda 1999). These copepods often account for 80 to $95 \%$ of zooplankton biomass in the surface zone (Vinogradov 1970) and are important prey for pelagic fishes, whales and seabirds (Nemoto 1963,
Takeuchi 1972, Odate 1994, Hunt et al. 1998, Mackas \& Tsuda 1999). Because of their apparent trophic importance, intensive studies on life history patterns have been made on these large grazing copepods (Miller et al. 1984, Miller \& Clemons 1988, Kobari \& Ikeda 1999, 2000, 2001a,b, Tsuda et al. 1999). According to Vinogradov \& Arashkevich (1969), in the western subarctic Pacific the most dominant copepod in terms of biomass is $N$. cristatus, followed by E. bungii, N. plumchrus (including $N$. flemingeri), Metridia okhotensis and $M$. 
pacifica, but almost nothing is known about the life history patterns of the 2 Metridia species in this region.

The calanoid copepods Metridia pacifica Brodsky (formally $M$. lucens or $M$. lucens var. pacifica, cf. Brodsky 1948) and M. okhotensis Brodsky are mediumor large-sized species; the former is distributed throughout the entire subarctic Pacific and the adjacent Japan, Bering and Okhotsk Seas and off the coast of California (Brodsky 1967), and the latter in the Okhotsk Sea, Bering Sea and possibly over the entire subarctic Pacific (Brodsky 1967, Minoda 1971, Coyle et al. 1990, Cooney et al. 2001, Ozaki et al. 2001). While Brodsky (1948) established M. pacifica as a new species, diagnostic features between $M$. pacifica and M. lucens have long been questioned among copepod taxonomists, and these 2 species were considered by some to be varieties of the same species. Bucklin et al. (1995), using mtDNA sequence data, confirmed that $M$. lucens and $M$. pacifica are distinct species.

Metridia pacifica has been known as a potential prey for pelagic chaetognaths in the western Subarctic Gyre (Terazaki 1998), and both M. pacifica and M. okhotensis are prey for the mesopelagic myctophid and gonostomatid fishes in the western subarctic Pacific (Gordon et al. 1985, Moku et al. 2000, Uchikawa et al. 2001). Nauplii of Metridia spp. have been reported as one of the most important prey items for the first-feeding larvae of walleye pollock Theragra chalcogramma in the coastal waters of southwestern Hokkaido, western subarctic Pacific (Nakatani 1995) and the Bering Sea (Hillgruber et al. 1995, Pinchuk \& Paul 1998). In the epipelagic zone of the eastern subarctic Pacific $M$. pacifica contributes substantially to the zooplankton biomass, especially during the fall-winter season when the large grazing copepods reside in the deep layers (Batchelder 1986a). The late-copepodites of $M$. pacifica (excluding adult males) are known to undergo an extensive diel vertical migration (Batchelder 1985, Hattori 1989, Hirakawa 1991, Hirakawa \& Imamura 1993). Integrated information about seasonal abundance, vertical migration and the life history of $M$. pacifica is presently available for the populations in the eastern subarctic Pacific (Batchelder 1985,1986a) and the Japan Sea (Hirakawa 1991, Hirakawa \& Imamura 1993). However, comparable information is currently lacking for the population of $M$. pacifica in the Oyashio region of the western subarctic Pacific.

Until the present study, almost nothing was known about seasonal features of population structure, abundance and life cycles of Metridia okhotensis. This may be partly due to the fact that $M$. okhotensis is an abundant species in the Okhotsk Sea, but is less abundant in other waters of the subarctic Pacific. According to Vinogradov \& Arashkevich (1969), most M. okhotensis in the Kurile-Kamchatka region live at less than $750 \mathrm{~m}$ depth. Coyle et al. (1990) recorded M. okhotensis in an Alaskan subarctic embayment during spring. Hattori (1989) documented the vertical distribution of $M$. okhotensis during day and night in the western subarctic Pacific.

As part of a research program to evaluate plankton dynamics in the Oyashio region, the present study aimed to document the vertical distribution, population structure, and life cycle of 2 dominant calanoid copepod species, Metridia pacifica and M. okhotensis, in this region by analyzing time-series samples. Overwintering stages have been identified, and the developmental pattern of the 2 species analyzed based on between-stage increments in body length and weight. The results are compared with Metridia spp. from other regions. Finally, differences in overwintering strategies between Metridia spp. and other large copepods (of the genera Neocalanus and Eucalanus) are discussed.

\section{MATERIALS AND METHODS}

Field sampling. Zooplankton samples were collected at nearly monthly intervals from 4 September 1996 through 5 October 1997 (Table 1 ) in the Oyashio region rectangle defined by $41^{\circ} 30^{\prime}$ to $42^{\circ} 30^{\prime} \mathrm{N}$ and $145^{\circ} 00^{\prime}$ to $146^{\circ} 00^{\prime} \mathrm{E}$, off southeastern Hokkaido (hereafter referred to as Site H, Fig. 1). Zooplankton were collected with a closing net $(60 \mathrm{~cm}$ mouth diameter, $100 \mu \mathrm{m}$ mesh size; Kawamura 1968, 1989) equipped with a Rigosha flow-meter in its mouth ring and a Tsurumi Seiki Kabushiki-Kaisha (TSK) depth-distance recorder or TSK RMD depth meter on its suspension cable to record sampling depth. The nets were towed vertically at a speed of $1 \mathrm{~m} \mathrm{~s}^{-1}$ through 5 discrete depths: surface to bottom of the thermocline (BT), BT-250 m, 250-500 m, 500-1000 m and 1000-2000 m. During the winter season, when the thermocline was

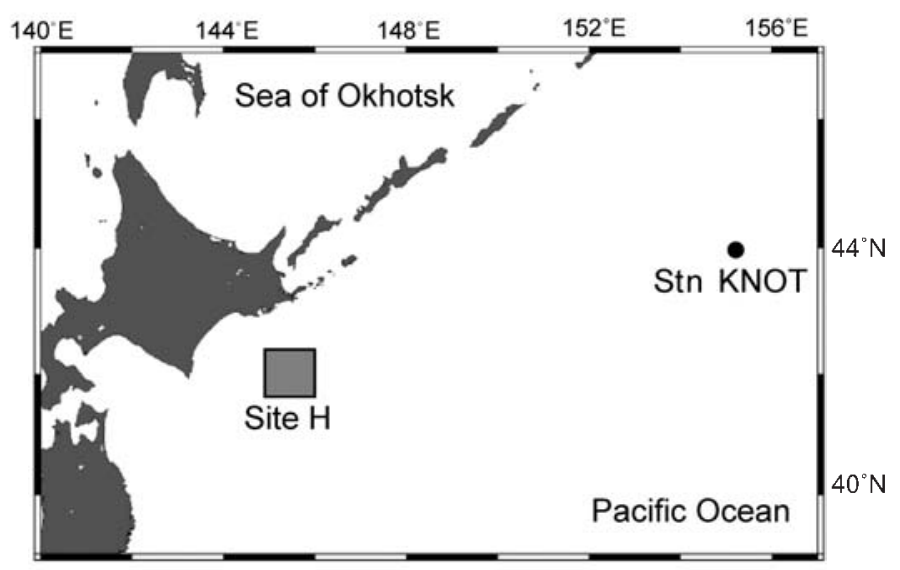

Fig. 1. Location of Site H and Stn KNOT in western subarctic Pacific 
Table 1. Zooplankton sampling data

\begin{tabular}{|llll|}
\hline Location/sampling date & \multicolumn{1}{c}{ Time (h local time) } & Vessel & \multicolumn{1}{c}{ Discrete sampling depth (m) } \\
\hline Site H & & & \\
4 September 1996 & 18:27-20:23, 07:28-09:26 & Oshoro-Maru & $0-30,30-250,250-500,500-1000,1000-1800$ \\
19 September 1996 & $17: 37-19: 44$ & Hokusei-Maru & $0-30,30-250,250-500,500-1000,1000-1500$ \\
2 October 1996 & $23: 25-02: 05$ & Hokusei-Maru & $0-30,30-250,250-500,500-1000,1000-1500$ \\
8 December 1996 & $01: 10-02: 48,06: 36-08: 50$ & Hokushin-Maru & $0-80,80-250,250-500,500-1000,1000-1700$ \\
13 January 1997 & $10: 00-12: 00$ & Hokko-Maru & $0-50,10-500,300-1700$ \\
20 February 1997 & $02: 30-05: 10$ & Hokushin-Maru & $0-100,100-250,250-500$ \\
17 March 1997 & $00: 55-03: 30$ & Hokko-Maru & $0-100,100-250,250-500,500-1000,1000-2000$ \\
11 April 1997 & $02: 40-04: 40,08: 20-10: 30$ & Hokusei-Maru & $0-100,100-250,250-500,500-1000,1000-1500$ \\
7 May 1997 & $23: 35-03: 20$ & Hokko-Maru & $0-100,100-250,500-1000,1000-2000$ \\
4 June 1997 & $18: 50-20: 09$ & Oshoro-Maru & $0-80,80-250,250-500,500-1000$ \\
23 June 1997 & $21: 23-23: 26$ & Hokusei-Maru & $0-20,20-250,250-500,500-1000,1000-2000$ \\
2 July 1997 & $19: 53-22: 08$ & Hokusei-Maru & $0-40,40-250,250-500,500-1000,1000-2000$ \\
17 August 1997 & $19: 45-21: 39$ & Oshoro-Maru & $0-80,80-250,250-500,500-1000,1000-2000$ \\
26 August 1997 & $10: 10-12: 01$ & Tansei-Maru & $0-20,20-250,250-500,500-1000,1000-2000$ \\
5 October 1997 & $20: 45-22: 20,15: 05-17: 15$ & Hokusei-Maru & $0-75,75-250,250-500,500-1000,1000-2000$ \\
Stn KNOT & & & \\
19-21 August 1998 & $09: 07-13: 28,22: 06-05: 02$ & Hakurei-Maru No. 2 & $0-100,100-200,200-500,500-1000,1000-1500$, \\
& & & $1500-2000,2000-3000,3000-4000$
\end{tabular}

not recognized, BT was assumed arbitrarily as $100 \mathrm{~m}$ depth. On 3 dates, 1 or more depth strata were not sampled. Data for missing samples were interpolated from the nearest samplings of that depth interval before and after the sampling dates (see Table 1). Samples to evaluate seasonal vertical distributions were collected during night hours except on 13 January 1997 and 26 August 1997. To investigate the diel vertical migration pattern, day-night samplings were conducted on 4 occasions, i.e. 9 September and 12 December 1996 and 11 April and 5 October 1997. After collection, zooplankton samples were immediately preserved in a $5 \%$ formalin-seawater solution buffered with borax. Temperature and salinity profiles were determined with a CTD system (Neil Brown, General Oceanics, or Sea Bird, Electronics) at each zooplankton sampling. Chlorophyll a profiles at Site $\mathrm{H}$ have been reported elsewhere (Kasai et al. 2001).

Additional day-night samplings were made on 19 to 21 August 1998 at Stn KNOT $\left(44^{\circ} \mathrm{N}, 155^{\circ} \mathrm{E}\right)$ (Fig. 1), which is located in the southwestern part of the Western Subarctic Gyre (Fig. 1). Stn KNOT was chosen because effects of the discharge of water from the Okhotsk Sea, which would influence the interpretation of population dynamics of zooplankton, are considered unlikely here (cf. Kono 1997). Zooplankton was collected with a vertical multiple plankton sampler (VMPS) $(100 \times 100 \mathrm{~cm}$ mouth-opening, $90 \mu \mathrm{m}$ mesh size; Terazaki \& Tomatsu 1997) from 200-500, 500-1000, 1000-1500, 1500-2000, 2000-3000 and 3000-4000 m. The samples were taken from the surface-100 and 100-200 m depths using a modified NORPAC net $(40 \times 40 \mathrm{~cm}$ mouth-diameter, $90 \mu \mathrm{m}$ mesh size; Motoda
1957). Details of the sampling program at Stn KNOT have been reported elsewhere (Yamaguchi et al. 2002).

Identification and enumeration. In the laboratory, Metridia pacifica and M. okhotensis were sorted from the entire or half aliquot of preserved zooplankton samples and counted under a dissecting microscope. The morphological features of adult males and females of both species have been given by Brodsky (1967, 1976). For identification of pre-adult copepodite stages of both species the description of $M$. lucens ( $=M$. pacifica) by Morioka (1976) and our own data gained from laboratory rearing of $M$. pacifica from eggs to adults (Padmavati \& Ikeda 2002) were used. Separation of males from females was possible from Copepodite Stage 4 (C4) for both species. Based on the condition of ovary development, C6 females were classified into 3 maturity stages adopting Batchelder's (1986b) system, except that 'immature' and 'partly mature' stages in his system were pooled as 'immature' stage in this study. In addition to 'immature' and 'mature' stages, a 'spent' stage was created in this study for specimens with empty ovaries and open genital pores.

Lipid deposition. In the course of our examination of specimens, we noticed a marked lipid deposition in C5 females of Metridia pacifica and C1, C5 and C6 females of $M$. okhotensis. To quantify this, specimens were classified into 3 types: rich, with having a large lipid globule exceeding half of the body length (Fig. 2a); medium, with a medium-sized lipid globule less than half of the body length); and poor, with no oil globule. Rich was not seen in C1 of $M$. okhotensis, so they were classified as 'medium' (Fig. 2b) and 'poor' only. 

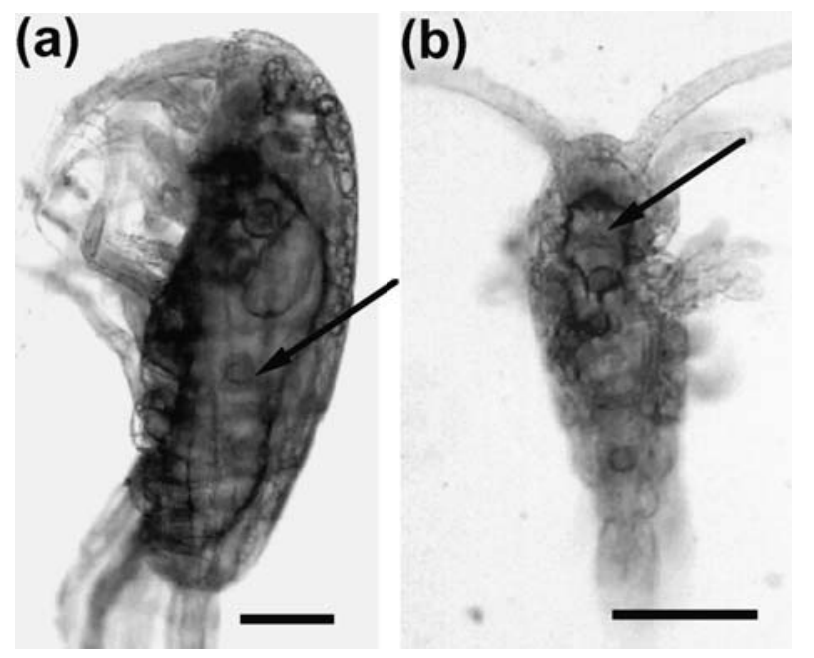

Fig. 2. Metridia pacifica and M. okhotensis. Lipid droplets (arrowed) of (a) 'rich' type Stage C5 of M. pacifica (lateral view), and (b) 'medium' type Stage $\mathrm{C} 1$ of $M$. okhotensis (dorsal view). Scale bars $=0.2 \mathrm{~mm}$

warm-core rings originating from the Kuroshio extension were seen in September of both 1996 and 1997, and from December 1996 to January 1997, as judged by measurements of temperature at $200 \mathrm{~m}\left(>4^{\circ} \mathrm{C}\right)$ and salinity in the 0 to $200 \mathrm{~m}$ layer ( $>33.5 \mathrm{psu}$ ) (Fig. 3b). Temperature and salinity in the 200 to $1500 \mathrm{~m}$ layer were stable and nearly constant at 2 to $3^{\circ} \mathrm{C}$ and 33.5 to $34.5 \mathrm{psu}$, respectively, throughout the year.

Phytoplankton biomass, estimated in terms of chlorophyll a concentrations, showed a marked seasonality

\section{RESULTS}

\section{Hydrography}

The western boundary current of the subarctic circulation in the North Pacific is called the 'Oyashio Current'. It flows southwestward along the Kuril Islands to the east coast of the northern Honshu, Japan, and then turns east at about $40^{\circ} \mathrm{N}$ (Reid 1973). During its journey, the properties of Oyashio Current water are modified as a result of exchanges with Okhotsk Sea water and Kuroshio water (Kono 1997). Because of its meandering flow pattern, isolated loops of the Kuroshio extension are often entrapped between the downstream and return flows of the Oyashio Current and are called 'warm core rings'.

Site $\mathrm{H}$ of this study is near the southern end of the southwestward alongshore flow of the Oyashio Current. Over the study period, surface temperatures ranged from $2{ }^{\circ} \mathrm{C}$ (March to April 1997) to $18^{\circ} \mathrm{C}$ (September to October 1996 and 1997) (Fig. 3a). Oyashio Current water, characterized by salinities from 33.0 to 33.3 psu and temperatures below $3^{\circ} \mathrm{C}$ (Ohtani 1971), occurred in the upper $150 \mathrm{~m}$ from February to April 1997. After April, less saline, seasonally warmed water (possibly originating from the Okhotsk Sea; T. Kono pers. comm.) occupied the upper $50 \mathrm{~m}$ of the water column. Surface temperatures above $10^{\circ} \mathrm{C}$ were observed in September to November 1996 and in June to October 1997, when the thermocline was well established at 20 to $50 \mathrm{~m}$ in the water column. Effects of
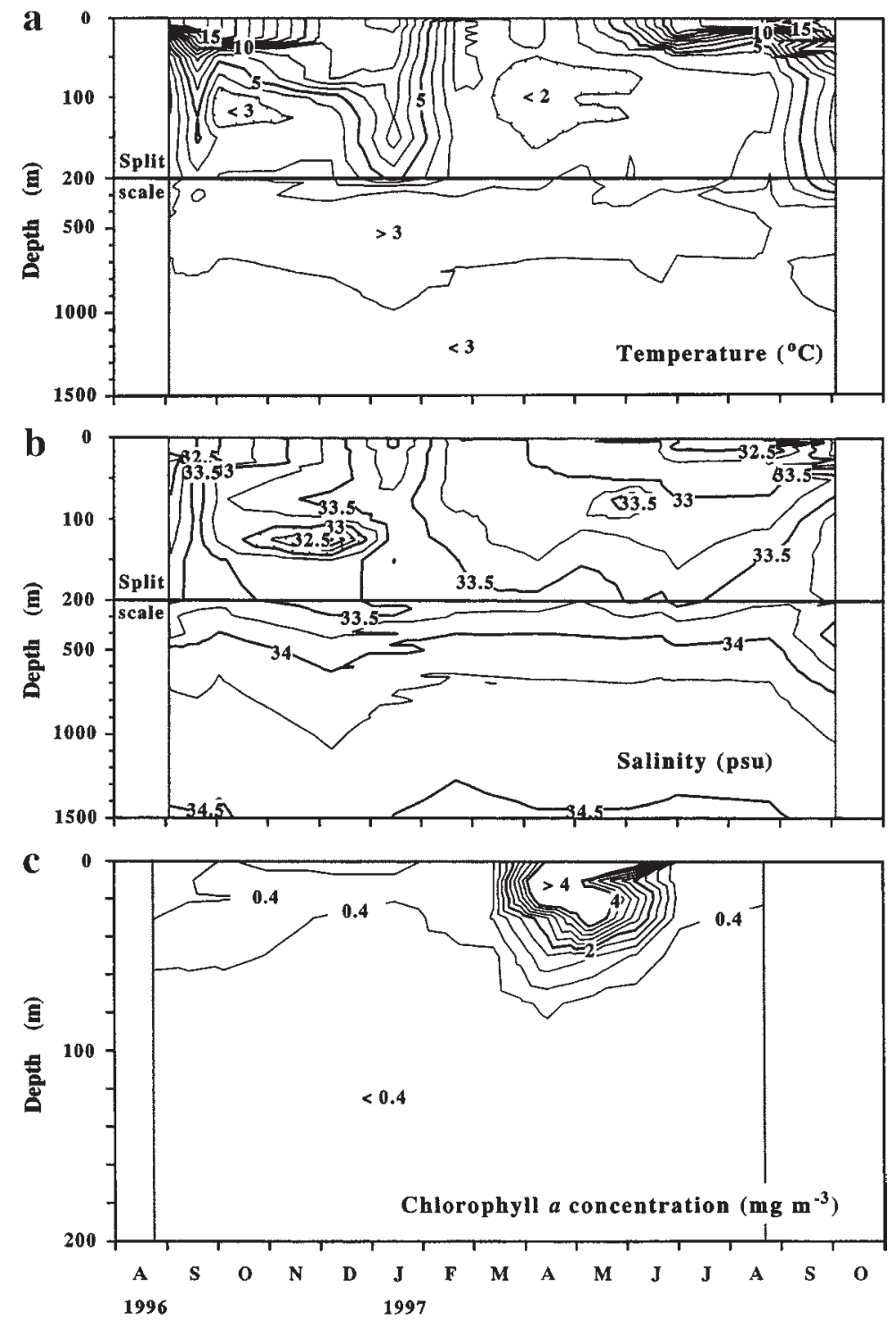

Fig. 3. Seasonal changes in (a) temperature, (b) salinity and (c) chlorophyll $a$ at Site H. Note different depth scale in (c) 
(Fig. 3c). Chlorophyll $a$ at the surface was around $0.4 \mathrm{mg} \mathrm{m}^{-3}$ from August 1996 to the end of February 1997, and then increased rapidly to $>9 \mathrm{mg} \mathrm{m}^{-3}$ in May 1997. During this period, concentrations above $2 \mathrm{mg}$ $\mathrm{m}^{-3}$ extended down to $50 \mathrm{~m}$ depth. The surface chlorophyll a concentrations had decreased to $2 \mathrm{mg} \mathrm{m}^{-3}$ by the end of June and to $0.4 \mathrm{mg} \mathrm{m}^{-3}$ toward the end of 1997. Chlorophyll a concentrations were $<0.4 \mathrm{mg} \mathrm{m}^{-3}$ below $100 \mathrm{~m}$ depth throughout the year.

\section{Seasonal vertical distribution}

Among the seasonal sampling data in Table 1, only nighttime data were used for this analysis. The C1, C2 and C3 stages of Metridia pacifica were distributed almost exclusively in the top $250 \mathrm{~m}$ of the water column throughout all seasons of the year (Fig. 4a). C4 individuals exhibited a much broader vertical distribution through the top $500 \mathrm{~m}$ of the water column) than the C1-C3 stages (Fig. 4b). The distribution pattern of
C5 changed markedly with season; they were abundant in the top $500 \mathrm{~m}$ during spring-early summer (March-August), and below $500 \mathrm{~m}$ or even $1000 \mathrm{~m}$ depth during September-February (Figs. 4c \& 5). Both C5 males and females showed a marked bimodal vertical distribution pattern in October through December 1996. The C6 females resided in the top $250 \mathrm{~m}$ of the water column while C6 males concentrated largely in the 250-500 $\mathrm{m}$ stratum throughout the year (Fig. 4d).

Of the copepodite stages of Metridia okhotensis, only C1, C5 and C6 females occurred throughout the year. C2, C3, C4 and C6 males were observed only seasonally. The C1, C5 and C6 females were distributed largely in the 250-1000 m depth strata (Fig. 6a,c,d). As exceptions, some fraction of the young stages (C1-C3) occurred in the surface layer (June, July and October 1997) and at 1000-2000 m depth (October 1996, and February-April, June, July, August and October 1997) (Fig. 6a). The vertical distribution pattern of $\mathrm{C} 4$ populations was similar to that of younger copepodites (Fig. 6b).

Abundance (ind. $\mathrm{m}^{-3}$ )
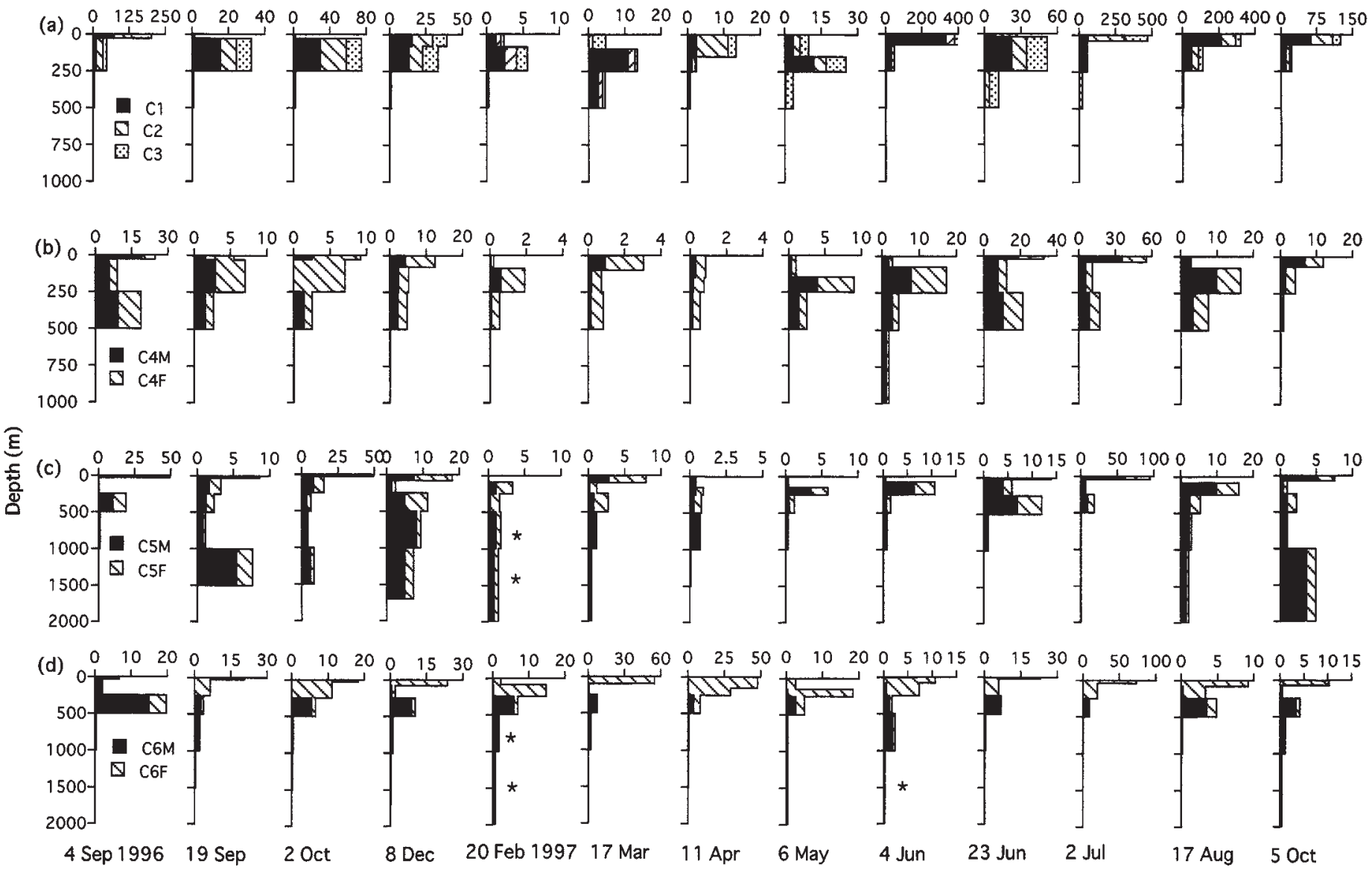

Fig. 4. Metridia pacifica. Seasonal changes in vertical distribution of (a) Stages C1-C3, (b) C4 males (M) and females (F), (c) C5 males and females, and (d) C6 males and females at Site H from September 1996-October 1997. Note that depth scale of (a) and (b) differ from that of (c) and (d). Asterisks denote interpolated values. Date of sampling is shown on bottom abscissa 


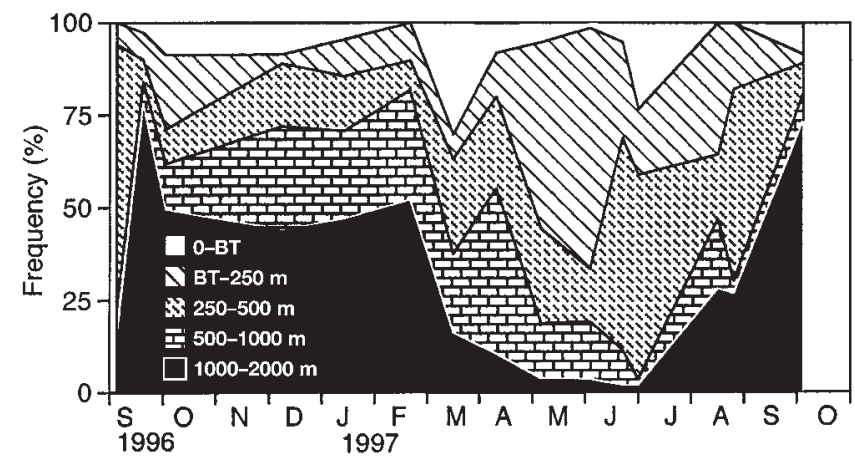

Fig. 5. Metridia pacifica. Seasonal changes in relative frequency of Stage C5 individuals in each stratum sampled at Site H from September 1996 to October 1997. BT: bottom of thermocline

\section{Day/night vertical distribution}

The young copepodites (C1-C3) of Metridia pacifica occurred mainly in the top $250 \mathrm{~m}$ of the water column both day and night throughout the 4 seasons, with no diel vertical migration (DVM) patterns (Fig. 7a). Only a small fraction of the $\mathrm{C} 4(<14 \%$ of the total population) and C5 $(<21 \%)$ populations migrated to the surface layer at night in September and December 1996. In April and October 1997, C4 and C5 occurred at the surface layer during both day and night (Fig. 7b,c). Most of the C5 population in December 1996 (44 and 88\% of the total population during daytime and nighttime, respectively) and in October 1997 (74 and 71\% of the total population during daytime and nighttime, respectively) were at 1000-2000 m, showing limited DVM. While part of the C6 female population migrated to the surface layer at night in September 1996 (15\% of the total population), December 1996 (59\%), April 1997 (44\%) and October 1997 (57\%), no DVM was seen in C6 males (Fig. 7d) (Kolmogorov-Smirnov test, $\mathrm{p}>0.05)$.

Young copepodites (C1-C3) of Metridia okhotensis were never found at the surface; instead, they were most abundant between 250 and $500 \mathrm{~m}$ depth

Abundance (ind. $\mathrm{m}^{-3}$ )
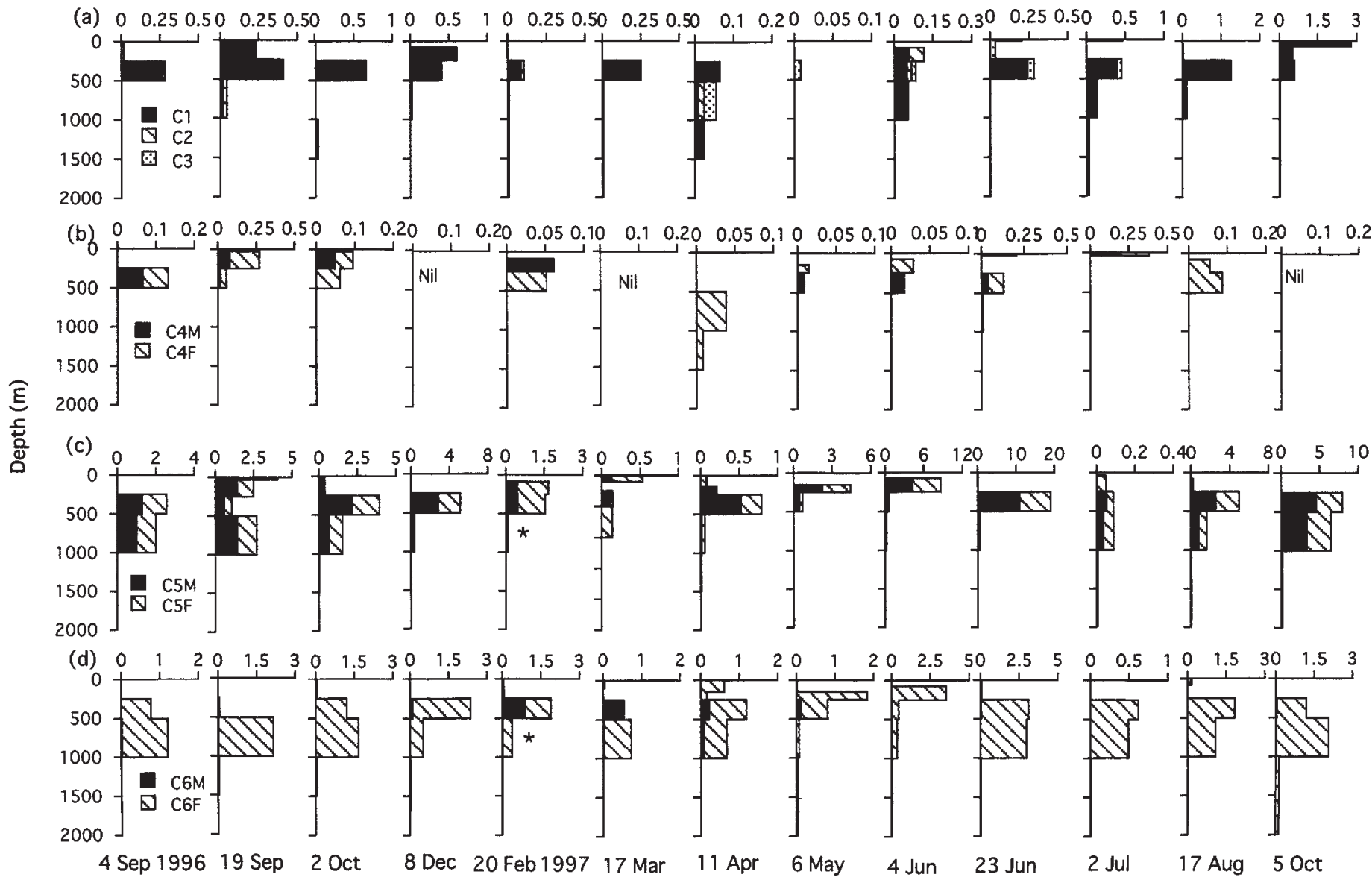

Fig. 6. Metridia okhotensis. Seasonal changes in vertical distribution of (a) Stages C1-C3, (b) C4 males and females, (c) C5 males and females, and (d) C6 males and females at Site H from September 1996-October 1997. Asterisks denote interpolated values. Date of sampling is shown on bottom abscissa 


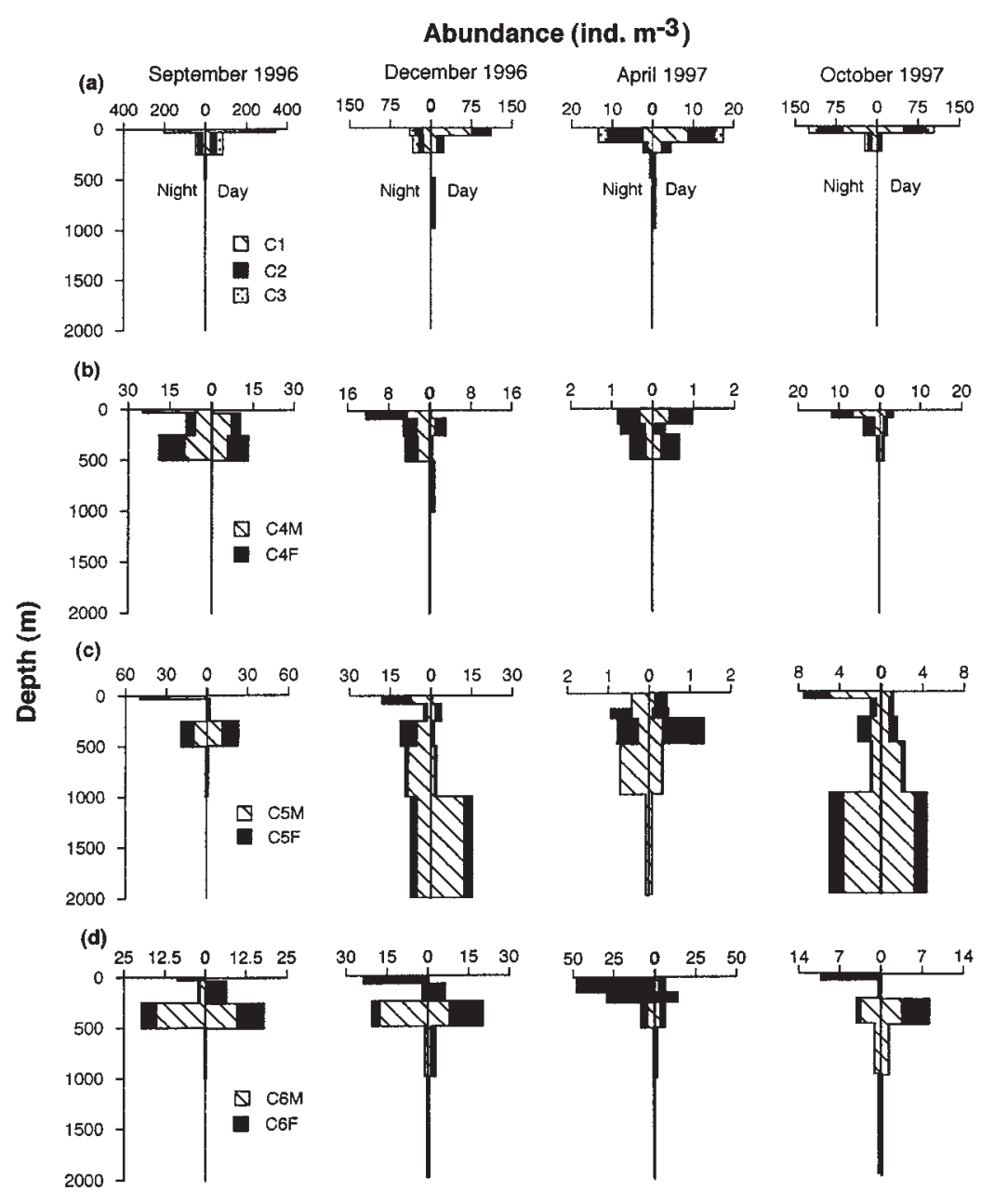

Fig. 7. Metridia pacifica. Day/night changes in vertical distribution of (a) Stages $\mathrm{C} 1$ to C3, (b) C4 males and females, (c) C5 males and females, and (d) C6 males and females at Site H. Date of sampling is shown on top abscissa

\section{Seasonal variations in abundance and population structure}

\section{Metridia pacifica}

All copepodite stages occurred throughout the year, although the abundance of each stage varied greatly with season (Fig. 9). C1 formed 2 abundance peaks, one in June (during the phytoplankton bloom) and the other in August 1997 (after the phytoplankton bloom). The maximum abundance of the $\mathrm{C} 2-\mathrm{C} 4$ was seen between the periods of the 2 C1 peaks. C5 were most abundant in October to December 1996: 2 successive abundance peaks of C6 females were seen, the first prior to the first $\mathrm{C} 1$ peak (early April 1997), and the last between the 2 C1 peaks (early July 1997). The abundance of C6 males was less marked seasonally.

The female:male ratios ranged from 0.8:1-4.7:1 (annual mean = 1.2:1) for C4, 0.34:1-1.1:1 (0.62:1) for C5, and from 0.47:1-8.1:1 (1.5:1) for C6. Immature C6 females with undeveloped ovaries comprised a large fraction (52-88\%) of the total adult female population throughout the year (Fig. 9b). Both mature and spent C6 females were found almost throughout the year, but the proportion they comprised of total females was low $(0-24$ and $7-43 \%$, respectively). Over the year, the proportion of mature females became higher in June to August, corresponding

both day and night over the year with no DVM pattern (Fig. 8a). Both C4 males and females were few in number and their vertical distribution patterns were somewhat similar to those of the C1-C3 stages. C4 was not found in daytime samples in December 1996 and April 1997; and in nighttime samples in October 1997; therefore seasonal changes in their DVM pattern could not be analyzed (Fig. 8b). However, during the September 1996 sampling, when C4 were collected both day and night, there was evidence of possible nighttime migration to the surface (Fig. 8b). Most C5 and C6 populations were found in 250-1000 $\mathrm{m}$ depth and showed no DVM pattern (Fig. 8c,d) (KolmogorovSmirnov test, $\mathrm{p}>0.30$ ). During April 1997, a part of the C6 population (33\% during daytime, 16\% at night) was seen in the surface layer during both day and night. in time with the seasonal peak in female C6 abundance (July).

In terms of stage composition of copepodites (grouped as C1-C3, C4, C5, C6 male and C6 female Fig. 10a) the copepodite population consisted mainly of younger copepodite stages (C1-C3) from May to September $(45-78 \%$ of the total population), especially in June (78\%) and August (73\%). From September to February, C5 was the most dominant stage, comprising $37-45 \%$ of the population. During the winter, the proportion of C5 decreased gradually toward spring of the next year and reached less than $20 \%$ of the total population by March. At the same time, the proportion of C6 males increased from December to February, and that of C6 females from January to April. These seasonal sequences in copepodite stage composition, together with the incidence of mature females throughout the year (Fig. 9b), sug- 


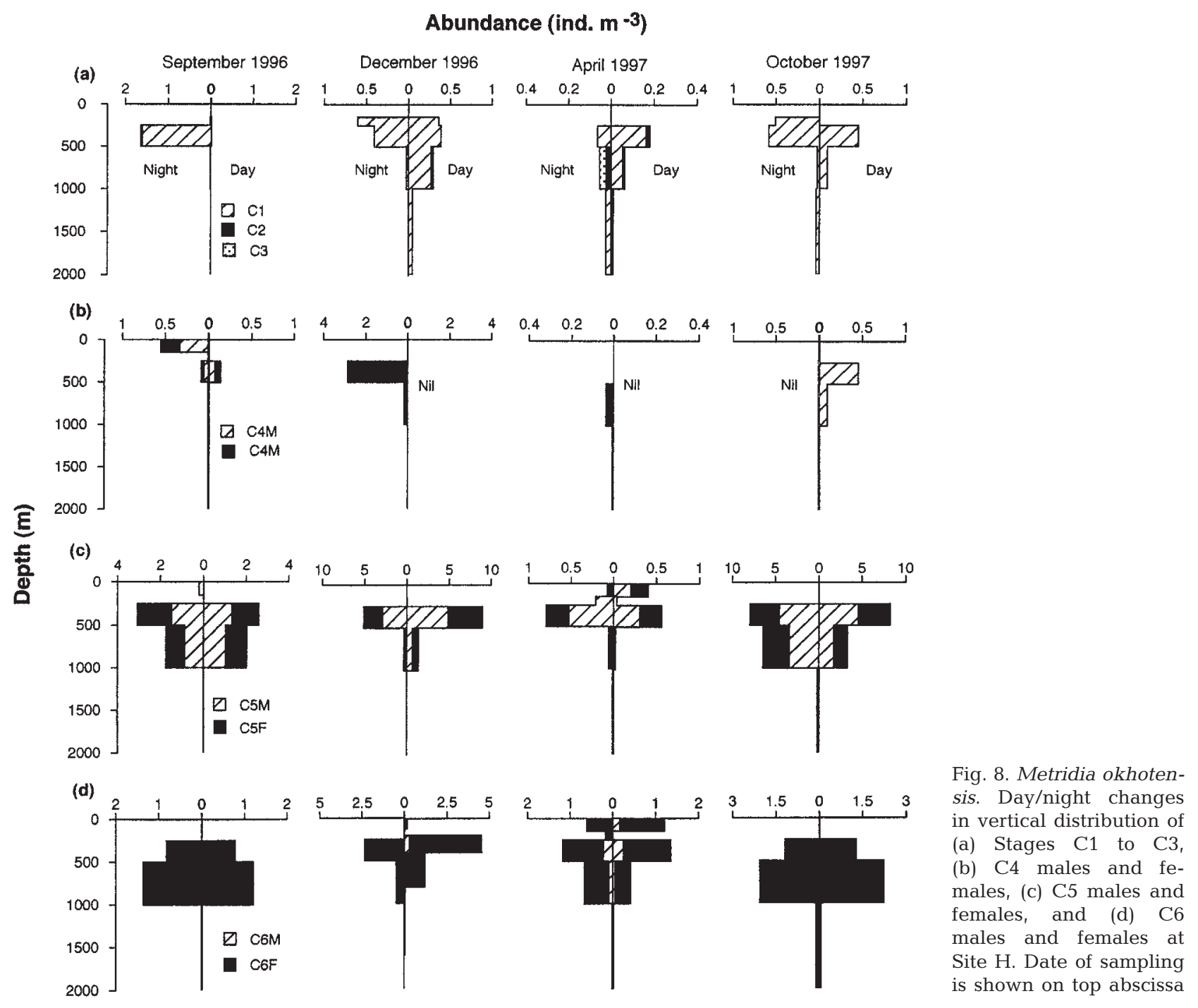

gest that while reproduction of this species may occur continuously year-round, 2 generations are completed in a year, the first generation yielding the abundance peak of $\mathrm{C} 1$ in early June and the C6 female peak in July. The second generation produced the peak of $\mathrm{C} 1$ in August, which did not develop to C6 until the following January-April.

\section{Metridia okhotensis}

C1 individuals occurred throughout the year, but their abundance was high from August to December and low from January to July (Fig. 11a). C2 and C3 occurred part of the year, the former in October 1996 and from February-August 1997, and the latter in September 1996 and from April-September 1997. C4 were found in all seasons but their seasonal abundance showed an irregular pattern. The overall abundance of C2, C3 and C4 was considerably less than that of C1. C5 occurred throughout the year and formed marked abundance peaks in late June and October 1997. C6 males did not occur in early October 1996 and July-August 1997. In contrast, C6 females were found throughout the year and their abundance peak was in late June 1997.

The occurrence of both $\mathrm{C} 4$ females and males was not continuous, and a female:male ratio based on annual mean abundance of each was 2.9:1. Female: male ratios varied with season from 0.8:1-2.5:1 (annual mean $=1.1: 1)$ for C5 and from 1.2:1-211:1 (13.1:1) for C6. Because of a large deposition of lipid in C6 females, observation of their gonads is often difficult, and therefore the classification of the maturity stage of this species may be less accurate than for females Metridia pacifica. Over the entire study period, matu- 
(a)

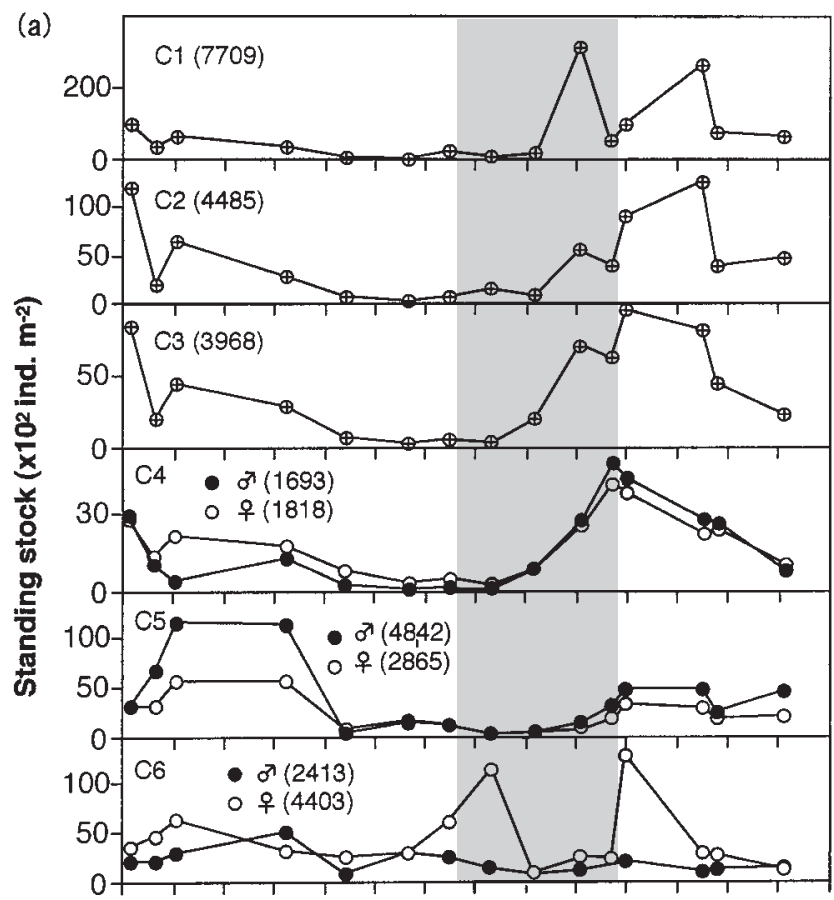

(b)

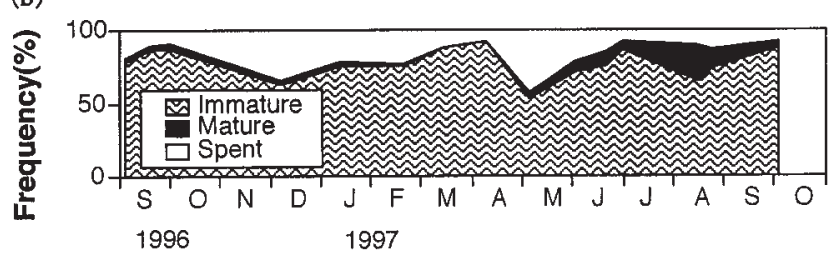

Fig. 9. Metridia pacifica. Seasonal changes in (a) standing stock of each developmental stage $(\mathrm{C} 1-\mathrm{C} 6)$ and (b) composition of maturity stages (immature, mature, spent) at Site $\mathrm{H}$ from September 1996-October 1997. In (a) values in parentheses $=$ annual means, shaded area $=$ phytoplankton bloom period

rity stage composition of $\mathrm{C} 6$ females was characterized by the almost exclusive predominance of immature individuals, fewer mature individuals (observed only in May and June 1997) and no spent individuals (Fig. 11b).

Copepodite population structure was characterized by the extreme predominance of older stages (C5 and C6) throughout the year (Fig. 10b). The greatest proportion of younger stages $(\mathrm{C} 1-\mathrm{C} 3)$ was $31 \%$ in early July 1997. As mentioned above, the C4 population was very small, comprising only $2-3 \%$ at most of the total population during late September to January. Within older stages, the proportion of C5 exceeded $50 \%(52-76 \%)$ of the total in September-December 1996 and April-June and August-October 1997, while that of C6 exceeded $50 \%$ of the total in January-March $(67-68 \%)$ and in June 1997 (57\%). These results would seem to sug- gest reproduction of Metridia okhotensis in late winter and recruitment of the resultant early copepodites in early summer (July), but the entire development sequence of the copepodites cannot be traced if one assumes the generation length of this species to be 1 yr or less (see 'Discussion').

\section{Lipid-deposition pattern}

For Metridia pacifica, C5 individuals classified as rich type increased gradually from July, reaching a peak in September-October and decreasing toward March-May (Fig. 12a). Medium-type individuals showed a similar pattern. Poor-type individuals comprised less than $50 \%$ of the C5 population from August to October and more than $50 \%$ from December to June. The annual mean composition of rich, medium and poor types was $8.9,32.7$ and $58.4 \%$, respectively.

In contrast to the $\mathrm{C} 1$ stage of Metridia pacifica, which contained no lipid droplets, many C1 specimens of M. okhotensis contained a small lipid droplet in the head part of the prosome. The $\mathrm{C} 1$ individuals classified as medium type comprised more than $60 \%$ of the $\mathrm{C} 1$ population throughout most seasons (Fig. $12 \mathrm{~b})$. The proportion of rich-type C5 individuals decreased from October 1996-March 1997, and then increased from April-September 1997 (Fig. 12c). Medium-type specimens showed a similar trend. Poor-type individuals were abundant from December to April. The annual mean composition of the 3 types of C5 was $24.4 \%$ for rich, $44.2 \%$ for medium and $31.4 \%$ for poor types. For C6 females, seasonal patterns of the 3 types were similar to those of C5 in general (Fig. 12d), but the proportion of rich type was greater (annual mean $=52.8 \%$ ) and the proportion of poor type was less in C6 $(15.5 \%)$ than the respective types in $\mathrm{C} 5$.

\section{Stn KNOT}

During zooplankton sampling in August 1998, surface temperature, salinity and chlorophyll a were $13.5^{\circ} \mathrm{C}, 32.7 \mathrm{psu}$, and $0.8 \mathrm{mg} \mathrm{m}^{-3}$, respectively, and depth profiles of these environmental parameters were similar to those observed at Site H in the same month of 1997 (August 1997, cf. Fig. 3). For details of hydrographic data for this sampling program, see Yamaguchi et al. (2002).

All copepodite stages of Metridia pacifica were found in the $0-500 \mathrm{~m}$ depth stratum during day and night (Fig. 13a). They were most numerous at $0-100 \mathrm{~m}$ depth during both day and night. Day-night differences in vertical distribution of the entire population 


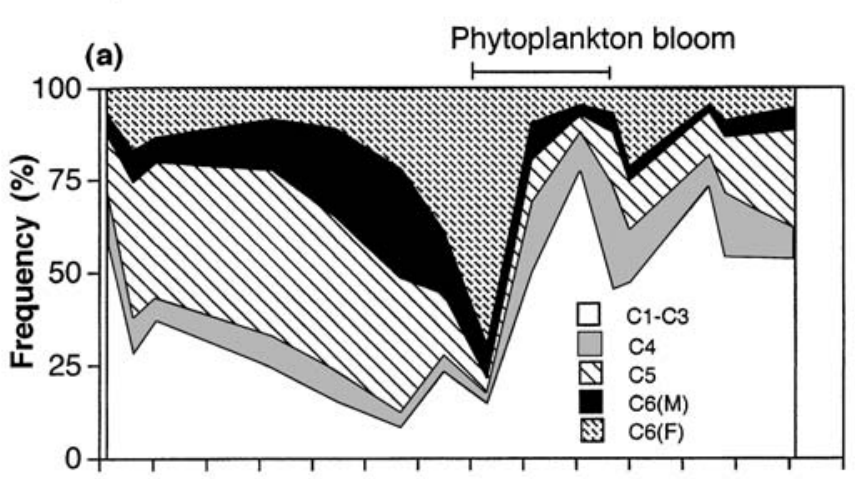

(b)

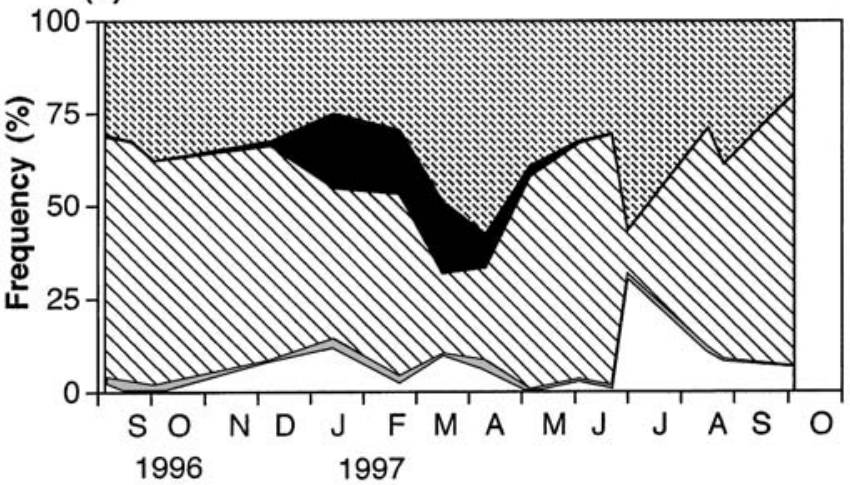

Fig. 10. (a) Metridia pacifica and (b) M. okhotensis. Seasonal changes in relative frequency of Stages C1-C3, C4, C5 and C6 males and females at Site H from September 1996 to October 1997

were not significant (Kolmogrov-Smirnov test, p > 0.3). However, DVM behavior was evident for older copepodite stages; e.g. most C4-C6 stages resided at 100-500 $\mathrm{m}$ depth during the daytime and ascended to 0-100 m depth at night (Fig. 13). The population structure was characterized by the predominance of $\mathrm{C} 1$ ( $24 \%$ of the total) and adult females (24\%), suggesting August to be well within their active reproduction seasons.

Metridia okhotensis occurred at 200-1000 m depth, and showed no DVM pattern (Fig. 13b). While day-night differences in vertical distribution of the entire population were not significant (KolmogrovSmirnov test, $p>0.1)$, a small fraction $(3 \%)$ of the population was found at 0-100 m depth only at night. In contrast to $M$. pacifica (see above), the population structure of $M$. okhotensis was dominated by C5 (males and females) and C6 (females), which together accounted for $93 \%$ of the total population. Young copepodites (C1-C4) and adult males were extremely scarce or absent (C3).

When the same season (August) is compared, the vertical distribution and population structure of Metridia pacifica and M. okhotensis at Stn KNOT are consistent with those observed at Site H.
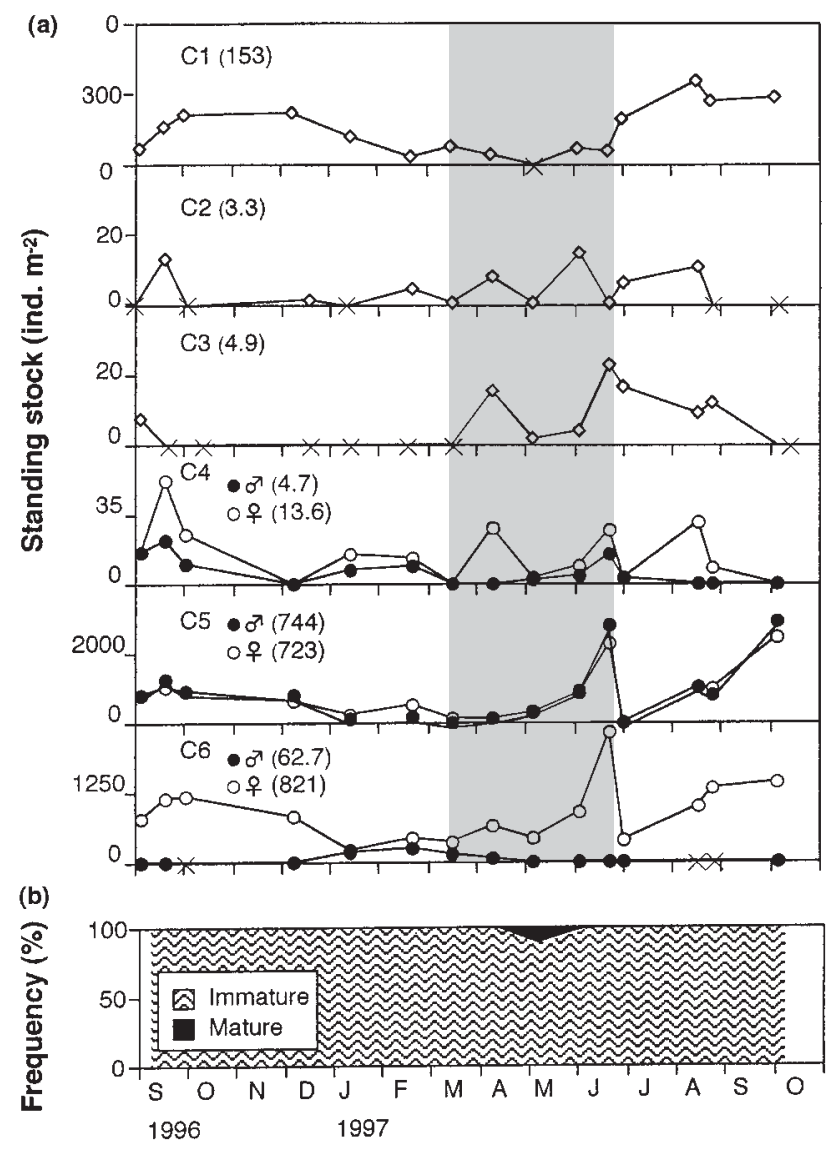

Fig. 11. Metridia okhotensis. Seasonal changes in (a) standing stock of each developmental stage (C1-C6) and (b) composition of maturity stages (immature, mature) at Site $\mathrm{H}$ from September 1996-October 1997. In (a) values in parentheses $=$ annual means, shaded area $=$ phytoplankton bloom period.

$x$ : no occurrence. Note differing ordinate scales in (a)

\section{DISCUSSION}

\section{Vertical distribution}

Seasonal distribution patterns of Metridia pacifica at Site $\mathrm{H}$ in the Oyashio region were characterized by the shallow occurrence $(<250 \mathrm{~m})$ of young copepodites (C1-C3) and C6 females, a slightly deeper occurrence (250-500 m) of C6 males, and a great variation in C5 from the surface layer to 1000-2000 depth (Fig. 5). The only information comparable to the present results is that of Batchelder (1985) at Stn P in the eastern subarctic Pacific. As a habitat for $M$. pacifica, Stn P differs from Site $\mathrm{H}$ of this study in that phytoplankton biomass at Stn P does not show clear seasonality throughout the year (0.1-0.6 mg chlorophyll $a \mathrm{~m}^{-3}$ ) although primary production reaches its maximum in May-July (cf. Welshmeyer et al. 1993). In contrast, the occurrence of a phytoplankton bloom (2-9 mg chlorophyll a $\mathrm{m}^{-3}$ ) between March and June is a regular annual event at 

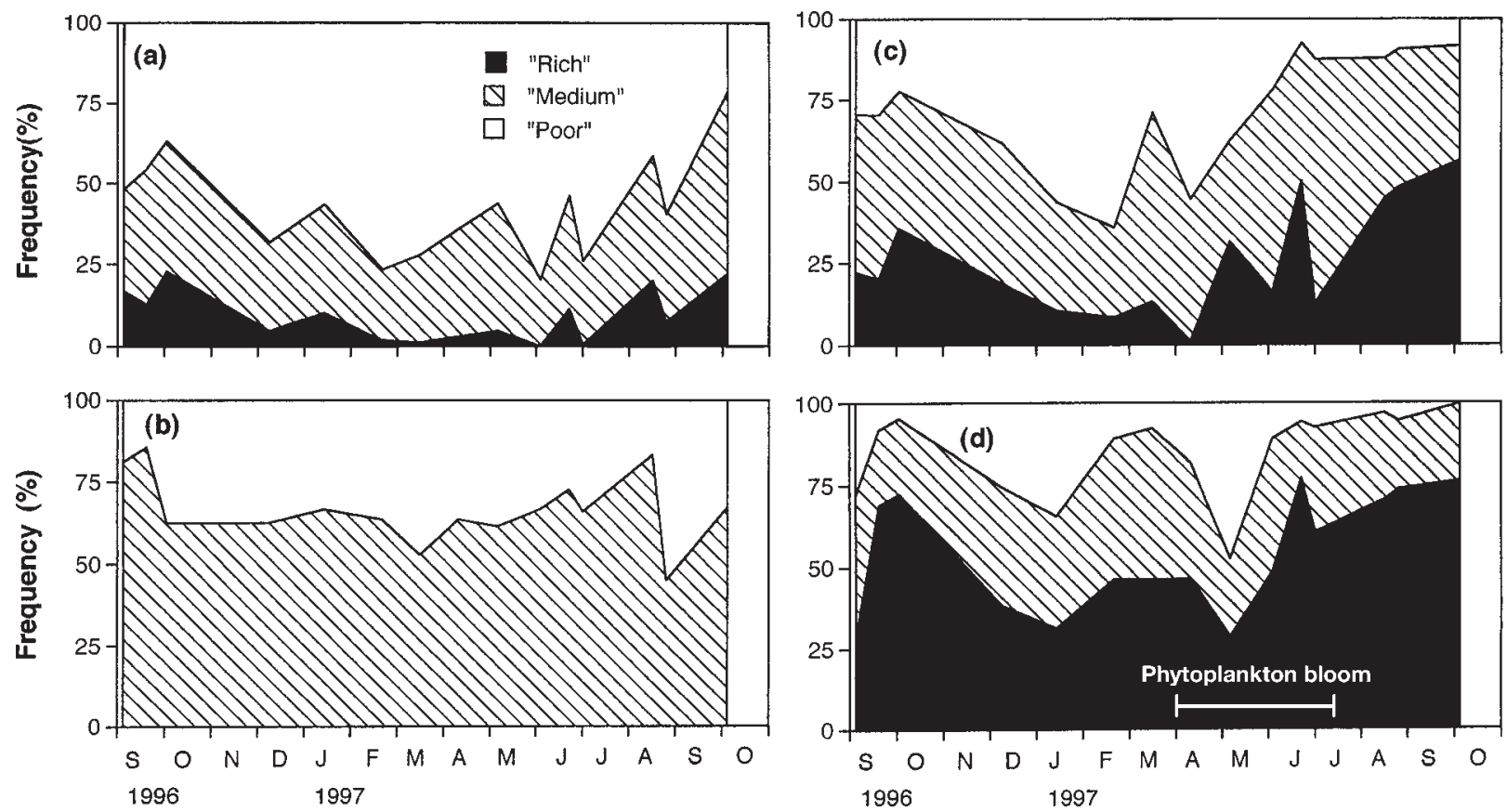

Fig. 12. Metridia pacifica and M. okhotensis. Seasonal changes in relative frequency of lipid deposition types (rich, medium, poor) of (a) Stage C5 M. pacifica, and (b) C1, (c) C5 and (d) C6 M. okhotensis at Site H from September 1996-October 1997. Note rich type did not occur for C1 M. okhotensis

Site $\mathrm{H}$ in the Oyashio region (Kasai et al. 2001). The annual range in surface temperatures at $\operatorname{Stn} P$ is narrower (6 to $14^{\circ} \mathrm{C}$; see Fig. 1 in Batchelder [1985]) than at Site $\mathrm{H}\left(2\right.$ to $18^{\circ} \mathrm{C}$, cf. present Fig. 2). Notwithstanding these different habitat conditions between Site $\mathrm{H}$ and $\mathrm{Stn} \mathrm{P}$, seasonal vertical distribution patterns of each copepodite stage of $M$. pacifica at these 2 sites were almost the same. Deeper excursions (>500 m depth) of C5 $M$. pacifica have also been reported in Toyama Bay, southern Japan Sea, where summer surface temperatures $\left(>26^{\circ} \mathrm{C}\right)$ rise beyond the limit of this species (Hirakawa \& Imamura 1993).
Fig. 13. (a) Metridia pacifica and (b) M. okhotensis. Day/night changes in vertical distributions (right) and their population structures (left) at Stn KNOT from 19-21 August 1998. Population structure represented by mean abundance of each developmental stage (no occurrence of C3 for M. okhotensis) in daytime and nighttime samplings (total in parentheses). (Note that despite sampling to $4000 \mathrm{~m}$ depth, neither species occurred beyond $2000 \mathrm{~m}$ depth) (a) Abundance (ind. $\mathrm{m}^{-3}$ )

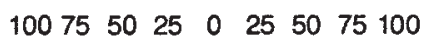
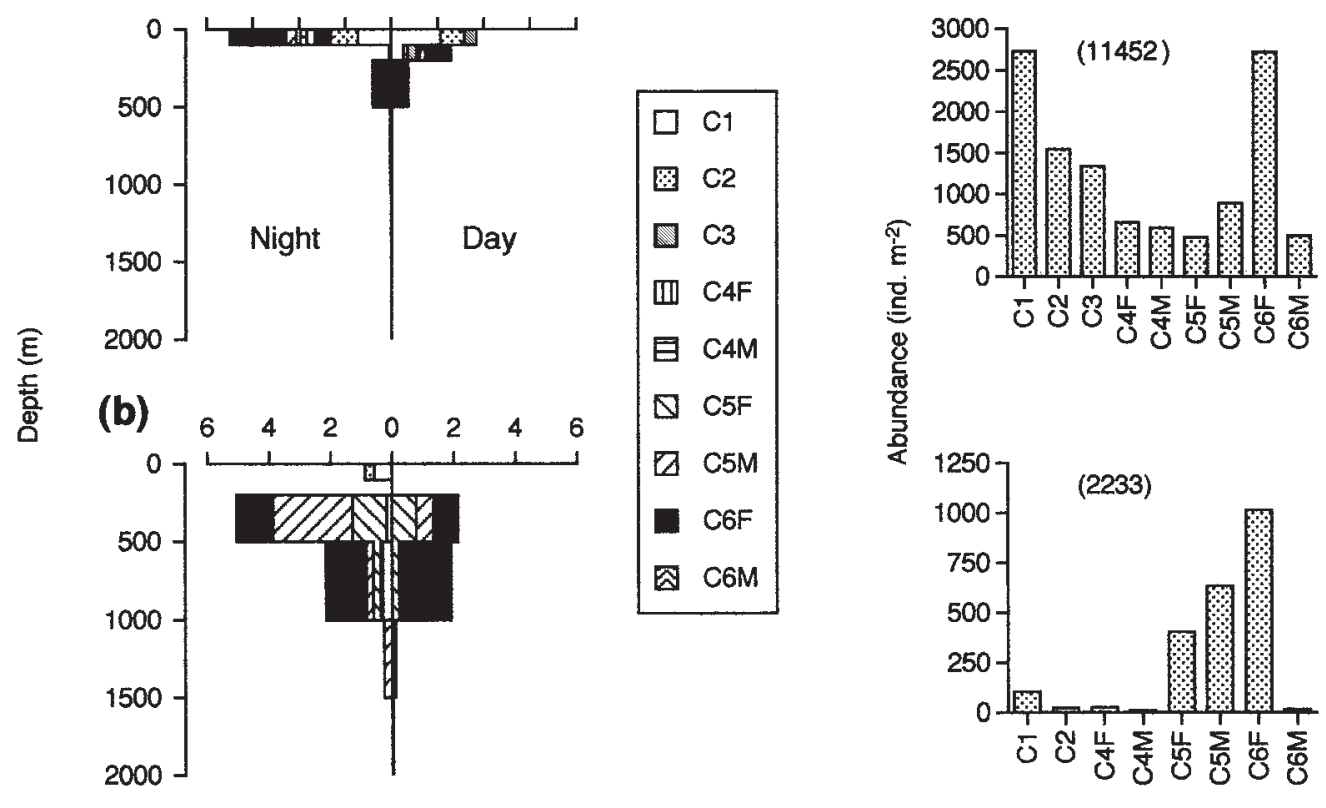

Copepodite stage 
Metridia okhotensis rarely occurred in the surface layer at Site H. Young stages (C1 to C4) occurred mostly from 250-500 m depth and older stages (C5, C6) from 250-1000 m depth (Fig. 6). Thus, these 2 sympatric species partition their distribution vertically for most of the year. Vertical separation of the habitat has already been noted for Neocalanus spp. in the subarctic Pacific (Mackas \& Tsuda 1999). While no comparable seasonal study on the vertical distribution of $M$. okhotensis is presently available, incidental records from the northwestern subarctic Pacific (50-1000 m: Minoda [1971]; 250-500 m deep: Hattori [1989]) and from the Bering Sea (200-1000 m: Minoda [1971]) are consistent with our results. As an exception, $M$. okhotensis in the northern and central Okhotsk Sea occur at shallow depths (25-100 m deep) (Russian literature compiled by Pinchuk \& Paul [2000]). Taking into account water temperatures in the depth stratum where $M$. okhotensis live in the northern and central Okhotsk Sea (near $0^{\circ} \mathrm{C}$ ), the major reason for the deeper distribution in the subarctic Pacific (including Site $\mathrm{H}$ ) and Bering Sea may be avoidance of warmer water near the surface. Submergence of cold-water zooplankton at lower latitudes or nearby areas where the surface is covered by warmer waters has been well documented (cf. Banse 1964 for review).

Many species belonging to the genus Metridia are known to perform DVM (Raymont 1983). Batchelder (1985) studied DVM behavior of M. pacifica at Stn P during July, August and January. His results showed that C3, C4, C5 (males and females) and C6 (females only), all of which were absent or rare at the surface during daytime, increased abundance significantly in the same layer at night, thus demonstrating normal DVM behavior (no observations for C1 and C2). The present observation on $M$. pacifica in September, December, April and October confirmed DVM for a fraction of the populations of females and males of $\mathrm{C} 4$ and $\mathrm{C} 5$ in 2 out of the 4 seasonal samplings, and C6 females in all these seasons (Fig. 7). The present results differ from those of Batchelder's (1985) in that C3 did not perform DVM in the present study. C3 occurred in the surface layer during both day and night.

Except for 1 isolated observation on C4 in September 1996, Metridia okhotensis did not perform DVM at Site H (Fig. 8). Hattori (1989) also noted the lack of DVM behavior for $M$. okhotensis at 2 stations in the western subarctic Pacific. However, in the Okhotsk Sea, where this species is abundant, Vinogradov \& Arashkevich (1969) reported extensive DVM (magnitude of 500-700 m) for M. okhotensis.

DVM of zooplankton is not a fixed behavior, but is flexible depending on environmental conditions such as light, temperature, oxygen, food availability, and presence or absence of predators (Lampert 1993, Hays et al. 1998, 2001 and references therein). According to a recent study, variations in the intensity of the turbulence of the upper layer (Incze et al. 2001) could also influence DVM behavior of zooplankton. The presence and absence of DVM within the same population, as was the case for Metridia pacifica in this study (Fig. 7) and in that of Hattori (1989), may have been due to individual variations in nutritional conditions (Hays et al. 1998, 2001). According to Hays et al. (2001), those individuals migrating to the surface layer to feed were characterized by lower lipid reserve. Unfortunately, we did not record lipid content in migrating and nonmigrating individuals in this study, and therefore Hays et al.'s (2001) hypothesis could not be verified.

\section{Life cycle}

Seasonal population structure data on a given zooplankton species at a fixed location may not be valid for analysis of its life cycle patterns because of possible transportation of the original population elsewhere by currents during the study period. In this respect, the present study site (Site $\mathrm{H}$ ) in the Oyashio region is characterized by a complex flow field (see 'Results'). However, the vertical distribution and population structure of Metridia pacifica and M. okhotensis at Stn KNOT in August 1998 (Fig. 13) are almost consistent with those observed at Site $\mathrm{H}$ in the same month of a different year, suggesting that spatial variations in the life cycle patterns of these 2 Metridia species between Site $\mathrm{H}$ and $\mathrm{Stn}$ KNOT are insignificant. Kobari \& Ikeda (1999, 2001a,b), comparing life history patterns of Neocalanus cristatus, $N$. plumchrus and $N$. flemingeri at Site $\mathrm{H}$ with those of individuals from various locations throughout the entire subarctic Pacific, noted the lack of any significant regional variation. Since these Neocalanus copepods are characterized by extensive ontogenetic migrations whose range covers the vertical distribution ranges of $M$. pacifica and $M$. okhotensis, and since the time-series samples used by Kobari \& Ikeda (1999, 2001a, b) were the same as those in this study, there is no reason to assume that the present results on the life cycle of Metridia spp. at Site $\mathrm{H}$ are exceptional.

\section{Metridia pacifica}

The occurrence of all copepodite stages including mature females throughout the year (Fig. 9a) is indicative of some reproduction of $M$. pacifica throughout the year at Site $\mathrm{H}$ in the Oyashio region. However, the stage composition data (Fig. 10a) suggests the occurrence of 2 major generations per year. Combining the 
seasonal vertical distribution patterns (Fig. 4), the schematic life cycle pattern of M. pacifica at Site H is presented in Fig. 14a. The first generation is represented by a peak in $\mathrm{C} 1$ abundance in early June, and the second generation by a $\mathrm{C} 1$ peak in mid-August. Based on the egg-hatching time and naupliar developmental time determined by laboratory-rearing experiments (Padmavati \& Ikeda 2002), spawning precedes peak $\mathrm{C} 1$ abundance by $1.5-2 \mathrm{mo}$. The timing of the abundance peak of $\mathrm{C} 6$ females which created the first generation (early April) and the second generation (early July) is consistent with this scenario. Thus, the first major spawning coincides with the phytoplankton bloom, and the second spawning occurs at the end of the bloom. Taking into account the wide sampling interval of this study (ca. 1 mo between samples), the generation length of the first generation can be estimated as 2-3 mo, whereas the second generation exhibits interrupted development, with the C5 copepodites remaining at depth $(>1000 \mathrm{~m})$ throughout autumn and early winter (generation length $=9-10 \mathrm{mo}$ ). Our laboratory experiments (Padmavati \& Ikeda 2002), in which eggs were successfully raised to $\mathrm{C} 6$ under saturated feeding conditions, suggested that $2-3$ mo generation times are reasonable if conditions (food,
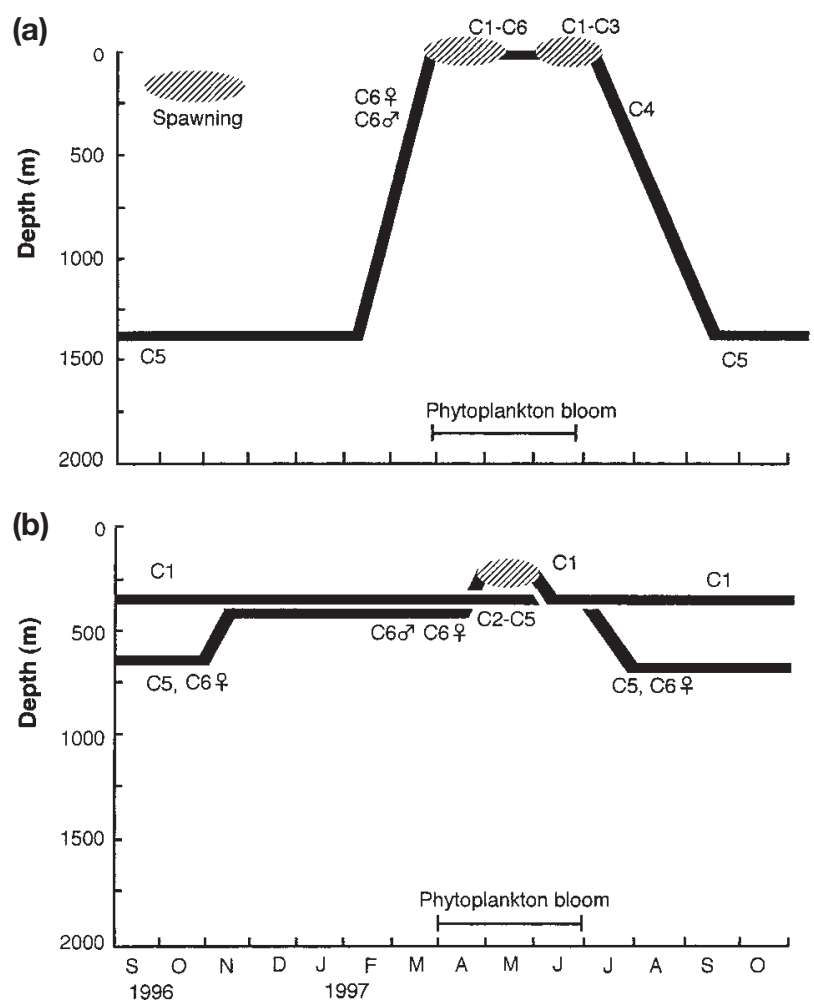

Fig. 14. (a) Metridia pacifica and (b) M. okhotensis. Schematic representation of life cycle trajectory combined with vertical migration patterns of major cohorts at Site $\mathrm{H}$ in Oyashio Current region temperature) remain suitable. Female:male ratios of $\mathrm{C} 4$ C5 and C6 stages varied greatly with season (Fig. 9a), as was observed for $M$. longa in Balsfjorden, northern Norway (Tande \& Grønvik 1983). The variations have been interpreted by sexual differences in development rates and in longevity for C6 (Tande \& Grønvik 1983).

At Stn P in the eastern subarctic Pacific, Batchelder (1986b) observed 3 marked peaks in the proportion of mature females of Metridia pacifica ( $>80 \%$ of the total females) in mid-April, early July and late September, and concluded that there were 3 generations per year. Each generation took 3 mo to mature to C6 females, but egg production by the third generation was delayed by 'supposedly unfavorable environmental conditions' in November to early January (Batchelder 1986b). Comparing these results at Stn P with those at Site $\mathrm{H}$, it is apparent that while the timing of initiation of the first (April) and second (July) generations is similar, a third generation is lacking at Site H. It is notable also that the proportion of mature specimens in C6 females over the year at Site H was considerably low (24\% at most, cf. Fig. 9 b) than that at Stn P. While no immediate explanation is presently available for the large differences in the proportion of mature females between our and Batchelder's (1986b) results, our wider sampling intervals (about 1 mo, compared with weekly intervals in Batchelder's study) may have missed peaks of maturation events of the females.

The study of Hirakawa \& Imamura (1993) in Toyama Bay, southern Japan Sea, revealed another example of regional variation in the life cycle of Metridia pacifica. In Toyama Bay, numerous nauplii occur during a phytoplankton bloom in mid-winter (January-February) and develop to C5 in early April. C5 specimens descend to deeper layers in summer to fall to avoid high lethal temperature in the surface layer $\left(>26^{\circ} \mathrm{C}\right)$, and molt to $\mathrm{C} 6$ end of the year. Thus, this species has only 1 generation per year in Toyama Bay.

These regional variations in the life cycle patterns of Metridia pacifica imply that the cue initiating the first generation of the year is the onset of the phytoplankton bloom for Site $\mathrm{H}$ and Toyama Bay populations. At Stn $\mathrm{P}$, there is no appreciable phytoplankton bloom, but the annual maximum of primary production is around May-June (cf. Welschmeyer et al. 1993) with a possible sub-maximum in October (Harrison et al. 1999). The number of generations per year appears to be related to thermal regimes of each habitat; the single generation of Toyama Bay may be attributable to 'aestivation' at depth during summer to avoid high temperatures (Hirakawa \& Imamura 1993). The annual range of surface temperatures at $\operatorname{Stn} \mathrm{P}\left(6\right.$ to $14^{\circ} \mathrm{C}_{i}$ Batchelder 1985) is much smaller than at Site H (2 to $18^{\circ} \mathrm{C}$; Fig. 3), suggesting that thermal conditions at Stn $\mathrm{P}$ are more favorable for $M$. pacifica. $M$. pacifica has 
been reported as probably having 4 generations in the waters joining Comandor Isles and Providens Bay, western Bering Sea (Heinrich 1962), and 1 generation in Anadyr Bay, northern Bering Sea (Heinrich 1962), and in the Okhotsk Sea (Shebanova 1994), but the lack of temperature and phytoplankton biomass data does not allow our hypothesis to be tested. Regional variations in copepod life cycles have been documented in other copepods such as Neocalanus flemingeri (Miller \& Terazaki 1989), Pseudocalanus minutus and P. newmani (Yamaguchi et al. 1998), Calanoides acutus (Atkinson et al. 1997), Rhincalanus gigas (Ward et al. 1997), Calanus finmarchicus (Planque et al. 1997) and C. hyperboreus (Hirche 1997).

\section{Metridia okhotensis}

While seasonal sequences of population structures of Metridia okhotensis (Fig. 11) and M. pacifica (Fig. 9) at Site $\mathrm{H}$ are broadly similar to each other, the former is markedly different from the latter in that the abundance peaks of $\mathrm{C} 1$ preceding the peaks of the subsequent copepodite stages were absent during the phytoplankton bloom despite the occurrence of mature C6 females in April-May. In addition, the population structure of $M$. okhotensis is characterized by extremely low abundance of C2-C4 stages (Fig. 11). Possible transportation of part of the population from the Okhotsk Sea to Site H via the Oyashio Current may be the cause of this anomalous feature in the seasonal sequence of the population structure of M. okotensis. It is known that $M$. okhotensis is very abundant in the Okhotsk Sea (see below). However, the population structure data at Stn KNOT, where any effect of the Okhotsk Sea water is unlikely, do not support theory (Fig. 13b). Indeed, the Stn KNOT data collected in August show the same features seen at Site $\mathrm{H}$ in the same month of a different year, i.e. extremely low abundance of $\mathrm{C} 2-\mathrm{C} 4$ (C3 was not found). A plausible explanation is that spawning is seasonal (in contrast to year-round spawning of $M$. pacifica), and the development of $\mathrm{C} 2-\mathrm{C} 4$ stages is rapid. A 2 yr life cycle scenario is most consistent with the observed seasonal sequence of $M$. okhotensis population structure at Site H (Fig. 14b). Spawning of eggs and development through the naupliar stages occur during the spring phytoplankton bloom of Year 1. By the end of the productive season and time of high surface temperatures, M. okhotensis have progressed only to C1, a phenomenon never yet observed in any other species. The C 1 descend to 250-500 $\mathrm{m}$ until the phytoplankton bloom in the following year, at which time they mature, mate and spawn the next cohort. According to this life cycle scenario, M. okhotensis is characterized by a much slower development and a much longer life span than M. pacifica. Female:male ratios of C6 M. okhotensis were extremely biased towards females (annual mean = 16.5:1), suggesting that the males are short-lived. The absence of spent females (Fig. 11b) suggests also that the females die off quickly after spawning. The 2 yr life cycle scenario (Fig. 14b) does not explain why the abundance of $\mathrm{C} 1$ (annual mean $=153$ ind. $\mathrm{m}^{-2}$, cf. Fig. 12b) is less than that of C5 (1467 ind. $\mathrm{m}^{-2}$ ). Possibly some significant peaks in $\mathrm{C} 1$ abundance were overlooked in this study because of low sampling frequencies (monthly) and/or some of the C5 individuals may live 1 more yr. To prove/disprove the tentative life cycle scheme proposed in this study, increased sampling effort is needed in the future.

There is no information available about the life cycle of the Metridia okhotensis population in the northern Okhotsk Sea except on their spawning season (JulyOctober) (Pinchuk \& Paul 2000). The spawning season of the Site $H$ population in the life cycle scenario suggested above is much earlier (April-May) than that of the Okhotsk Sea population. Considering that the phytoplankton bloom is a major driving force in the life cycle of $M$. okhotensis (and $M$. pacifica also), regional differences in the spawning season of $M$. okhotensis may reflect differences in the timing of phytoplankton production in the 2 regions. Analyzing coastal zone color scanner (CZCS) data, Saitoh et al. (1996) noted 2 seasonal surface chlorophyll a maxima, one in April-June and the other in August-November in the entire Okhotsk Sea. Dissimilar life cycle patterns of the grazing copepod Neocalanus cristatus at Site H and in the Okhotsk Sea have already been reported by Kobari \& Ikeda (1999).

In the central and northern Okhotsk Sea, Metridia okhotensis occur very abundantly, and their biomass is reported to be greater than that of $M$. pacifica (Pinchuk \& Paul 2000). In contrast, M. okhotensis was less abundant than $M$. pacifica at Site H. Considering thermal conditions at the distribution depth of $M$. okhotensis in the northern and central Okhotsk Sea (as low as $\sim 0^{\circ} \mathrm{C}$ ), it is evident that $M$. okhotensis is adapted to colder temperatures than M. pacifica. For Metridia spp. copepods living in low water temperatures (near $0^{\circ} \mathrm{C}$ ), generation lengths as long as 2 yr have been reported for $M$. gerlachei in the Weddell Sea, Antarctica, although this species is known to have 1 or more life cycles per year in waters near the Antarctic Convergence and Gerlache Strait, Antarctica (Huntley \& Escritor 1992, Kurbjeweit 1993).

\section{Feeding conditions and overwintering strategies}

Observations on feeding appendages (Arashkevich 1969, Romano et al. 1999), gut contents (Hattori 1989, 
Romano et al. 1999) and laboratory feeding experiments (Haq 1967) all suggest that Metridia spp. living in the epipelagic realm of the ocean are capable of feeding on phytoplankton, protozoans, copepods and even detritus. Nevertheless, the present results suggest strongly that the phytoplankton bloom (mostly diatoms) plays an integral role, directly or indirectly, in inducing spawning and facilitating rapid development of both M. pacifica and M. okhotensis in the Oyashio region. Diatoms sink at a speed of approximately $175 \mathrm{~m}$ $\mathrm{d}^{-1}$ in the subarctic Pacific, regardless of taxa, size or morphology (Takahashi 1986); thus they may reach the habitat depth of $M$. okhotensis (250-1000 m) in 1.4-5.7 d (250 or 1000/175). According to a recent study (Shinada et al. 2001), microzooplankton (ciliates, flagellates, copepod nauplii) becomes abundant after the phytoplankton bloom in the Oyashio region. Considering the broad diet of Metridia spp. it is obvious that these microzooplankton, together with phytoplankton and mesozooplankton, could be important food sources for repeated generations of both M. pacifica and M. okhotensis in the Oyashio region. However this raises the question: How do these copepods survive during winter when all these food resources become depleted in the water column?

For grazing copepods living in high-latitude seas where phytoplankton abundance is highly seasonal, mechanisms for surviving the phytoplankton-poor winter season have been a long-standing issue. Atkinson (1998), working on copepods in the Southern Ocean, classified mechanisms into 3 types, i.e. (1) herbivory in summer, a short reproductive period and winter diapause at depth; (2) a predominantly omnivorous/detritivorous diet, an extended period of feeding, growth and reproduction, and less reliance on diapause at depth; (3) overwintering and feeding within sea ice as early nauplii or copepodites. While the third type is not applicable to oceanic copepods in the subarctic North Pacific since there is no ice-cover in winter, the first type has been postulated for such copepods as Neocalanus cristatus, $N$. plumchrus, $N$. flemingeri and Eucalanus bungii in this region (Miller et al. 1984, Kobari \& Ikeda 1999, 2000, 2001a,b, Tsuda et al. 1999, Shoden 2000). Specimens in diapause at depth have large accumulations of body lipid (mostly in the form of wax ester, cf. Hagen \& Schnack-Schiel 1996, Saito \& Kotani 2000) in the body, cease feeding, are neutrally buoyant (= motionless) and have reduced metabolism. Lipid deposition in the body and its continuous reduction through winter, as observed for overwintering C5 Metridia pacifica (Fig. 12a) and C5 and C6 M. okhotensis (Fig. 12c, d) in this study, has also been noted for $M$. longa in Norwegian arctic fjords and the Barents Sea (Hopkins et al. 1985), and M. gerlachei in the Southern Ocean (Hagen \& Schnack-
Schiel 1996). For overwintering Neocalanus spp. and $E$. bungii that have ceased feeding at depth, the energy needed for metabolism and gonad development is fueled by stored lipid only. Conversely, the energy needs of overwintering Metridia spp. appear to be supplied by both feeding and stored lipid. Dependence on dual energy sources by Metridia spp. may be due to a higher energy requirement to sustain continuous glide-swimming at depth (in contrast to Neocalanus spp. and E. bungii, which largely remain notionless in the water column). Greater proportions of rich-type specimens of $M$. okhotensis than M. pacifica (Fig. 12a,c,d) may suggest that overwintering specimens of the former are less dependent on a year-round energy supply (continuous feeding) than those of the latter. For M. okhotensis, the seasonal pattern of lipid deposition was less marked in Stage C1 (Fig. 12b) than in Stages C5 or C6 (Fig. 12C,d). Perhaps the lipid droplets in $\mathrm{C} 1$ individuals are deposited in eggs (as has been postulated for Paraeuchaeta elongata, cf. Ikeda \& Hirakawa 1996) and, because of their smaller size, food supply in the surface layer is sufficient for them throughout the year (food concentrations critical for the survival of copepods decrease with decreasing body size, cf. Vidal 1980).

Evidence suggests that overwintering Metridia spp. are not in diapause, e.g. (1) oxygen consumption data for M. pacificus in the southern Japan Sea (Ikeda \& Hirakawa 1998), (2) lipid, metabolic enzyme and gutfluorescence data for M. pacificus in the San Diego Trough, eastern subarctic Pacific (Ohman et al. 1998), (3) gut content, digestive enzyme activity and oxygen consumption data for $M$. longa in Norwegian fjords (Båmstedt et al. 1985), (4) ammonia excretion data for M. gerlachei in the Southern Ocean (Huntley \& Nordhausen 1995). This evidence, combined with the broad feeding habits of Metridia spp., indicates that the overwintering mechanism of M. pacifica and M. okhotensis recorded in this study is consistent with Type 2 of Atkinson (1998).

Acknowledgements. We are grateful to H. P. Batchelder for reviewing earlier drafts of this paper; his constructive comments significantly improved the manuscript. Thanks are extended to D. L. Mackas and 2 anonymous reviewers for valuable comments.

\section{LITERATURE CITED}

Arashkevich EC (1969) The food and feeding of copepods in the northwestern Pacific. Okeanologiya 9:695-709

Atkinson A (1998) Life cycle strategies of epipelagic copepods in the Southern Ocean. J Mar Syst 15:289-311

Atkinson A, Schnack-Schiel SB, Ward P, Marin V (1997) Regional differences in the life cycle of Calanoides acutus (Copepoda: Calanoida) within the Atlantic sector of the Southern Ocean. Mar Ecol Prog Ser 150:99-111 
Båmstedt U, Tande KS, Nicolajsen H (1985) Ecological investigations on the zooplankton community of Balsfjorden, northern Norway: physiological adaptations in Metridia longa (Copepoda) to the overwintering period: In: Gray JS, Christiansen ME (eds) Marine biology of polar regions and the effects of stress on marine organisms. John Wiley \& Sons, Chichester, p 313-327

Banse K (1964) On the vertical distribution of zooplankton in the sea. Prog Oceanogr 2:55-125

Batchelder HP (1985) Seasonal abundance, vertical distribution, and life history of Metridia pacifica (Copepoda: Calanoida) in the oceanic subarctic Pacific. Deep-Sea Res 32:949-964

Batchelder HP (1986a) Phytoplankton balance in the oceanic subarctic Pacific: grazing impact of Metridia pacifica. Mar Ecol Prog Ser 34:213-225

Batchelder HP (1986b) A staining technique for determining copepod gonad maturation: application to Metridia pacifica from the northeast Pacific Ocean. J Crustac Biol 6: 227-231

Brodsky KA (1948) The pelagic Copepoda in the Japan Sea. Tr Pac Sci Inst Fish Oceanol 26:3-130 (in Russian)

Brodsky KA (1967) Calanoida of the far eastern seas and polar basins of the USSR. Israel Program for Scientific Translations, Jerusalem

Brodsky KA (1976) A description of male Metridia okhotensis Brodsky (Calanoida, Metridiidae). In: Explorations of the fauna of the seas, XX(XXVIII) N. Marine plankton (systematics and faunistics). Academy of Sciences USSR, Moscow, p 4-5

Bucklin A, Frost BW, Kocher TD (1995) Molecular systematics of six Calanus and three Metridia species (Calanoida: Copepoda). Mar Biol 121:655-664

Cooney RT, Coyle KO, Stockmar E, Stark C (2001) Seasonality in surface-layer net zooplankton communities in Prince William Sound, Alaska. Fish Oceanogr 10(Suppl 1):97-109

Coyle KO, Paul AJ, Ziemann DA (1990) Copepod populations during the spring bloom in the Alaskan subarctic embayment. J Plankton Res 12:759-797

Gordon JDM, Nishida S, Nemoto T (1985) The diet of mesopelagic fish from the Pacific coast of Hokkaido, Japan. J Oceanogr Soc Jap 41:89-97

Hagen W, Schnack-Schiel SB (1996) Seasonal lipid dynamics in dominant Antarctic copepods: energy for overwintering or reproduction? Deep-Sea Res 43:139-158

Haq SM (1967) Nutritional physiology of Metridia lucens and M. longa from the Gulf of Maine. Limnol Oceanogr 12:40-51

Harrison PJ, Boyd PW, Varela DE, Takeda S, Shiomoto A, Odate T (1999) Comparison of factors controlling phytoplankton productivity in the NE and NW subarctic Pacific gyres. Prog Oceanogr 43:205-234

Hattori H (1989) Bimodal vertical distribution and diel migration of the copepods Metridia pacifica, M. okhotensis and Pleuromamma scutullata in the western North Pacific Ocean. Mar Biol 103:39-50

Hays GC, Webb PI, Frears SL (1998) Diel changes in the carbon and nitrogen content of the copepod Metridia lucens. J Plankton Res 20:727-737

Hays GC, Kennedy H, Frost BW (2001) Individual variability in diel vertical migration of a marine copepod: why some individuals remain at depth when others migrate. Limnol Oceanogr 46:2050-2054

Heinrich AK (1962) On the production of copepods in the Bering Sea. Int Rev Gesamten Hydrobiol 47:465-469

Hillgruber N, Haldorson LJ, Paul AJ (1995) Feeding selectivity of larval walleye pollock Theragra chalcogramma in the oceanic domain of the Bering Sea. Mar Ecol Prog Ser 120:1-10

Hirakawa K (1991) Vertical distribution and reproduction of planktonic copepods in Toyama Bay, southern Japan Sea, with special reference to Metridia pacifica. Bull Plankton Soc Jap Spec Vol: 373-382

Hirakawa K, Imamura A (1993) Seasonal abundance and life history of Metridia pacifica (Copepoda: Calanoida) in Toyama Bay, southern Japan Sea. Bull Plankton Soc Jap 40:41-54

Hirche HJ (1997) Life cycle of the copepod Calanus hyperboreus in the Greenland Sea. Mar Biol 128:607-618

Hopkins CCE, Tande KS, Grønvik S, Sargent JR, Schweder T (1885) Ecological investigations of the zooplankton community of Balsfjorden, northern Norway: growth, and quantification of condition, in relation to overwintering and food supply in Metridia longa, Calanus finmarchicus, Thysanoessa inermis and Thysanoessa raschi. In: Gray JS, Christiansen ME (eds) Marine biology of polar regions and effects of stress on marine organisms. John Wiley \& Sons, Chichester, p 83-101

Hunt GL, Russell RW, Coyle KO, Weingartner T (1998) Comparative foraging ecology of planktivorous auklets in relation to ocean physics and prey availability. Mar Ecol Prog Ser 167:241-259

Huntley ME, Escritor F (1992) Ecology of Metridia gerlachei Giesbrecht in the western Bransfield Strait, Antarctica. Deep-Sea Res 39:1027-1055

Huntley ME, Nordhausen W (1995) Ammonium cycling by Antarctic zooplankton in winter. Mar Biol 121:457-467

Ikeda T, Hirakawa K (1996) Early development and estimated life cycle of the mesopelagic copepod Paraeuchaeta elongata in the southern Japan Sea. Mar Biol 126:261-270

Ikeda T, Hirakawa K (1998) Metabolism and body composition of zooplankton in the cold mesopelagic zone of the southern Japan Sea. Plankton Biol Ecol 45:31-44

Incze LS, Hebert D, Wolff N, Oakey N, Dye D (2001) Changes in copepod distributions associated with increased turbulence from wind stress. Mar Ecol Prog Ser 213:229-240

Kasai H, Saito H, Kashiwai M, Taneda T and 5 others (2001) Seasonal and interannual variations in nutrients and plankton in the Oyashio region: a summary of a 10 -year observation along the A-line. Bull Hokkaido Natl Fish Res Inst 65:55-134

Kawamura A (1968) Performance of Peterson type closing net. Bull Plankton Soc Jpn 15:11-12

Kawamura A (1989) Fast sinking mouth ring for closing NORPAC net. Bull Jpn Soc Sci Fish 55:1121

Kobari T, Ikeda T (1999) Vertical distribution, population structure and life cycle of Neocalanus cristatus (Crustacea: Copepoda) in the Oyashio region, with notes on its regional variations. Mar Biol 134:683-696

Kobari T, Ikeda T (2000) Life cycle of Neocalanus species in the Oyashio region. Bull Plankton Soc Jpn 47:129-135 (in Japanese with English abstract)

Kobari T, Ikeda T (2001a) Life cycle of Neocalanus flemingeri (Crustacea: Copepoda) in the Oyashio region, western subarctic Pacific, with notes on its regional variations. Mar Ecol Prog Ser 209:243-255

Kobari T, Ikeda T (2001b) Ontogenetic vertical migration and life cycle of Neocalanus plumchrus (Crustacea: Copepoda) in the Oyashio region, with notes on its regional variations in body size. J Plankton Res 23:287-302

Kono $\mathrm{T}$ (1997) Modification of the Oyashio water in the Hokkaido and Tohoku areas. Deep-Sea Res I 44:669-688

Kurbjeweit F (1993) Reproduction and life cycles of dominant copepod species from the Weddell Sea, Antarctica. Ber 
Polarforsch 129:1-237

Lampert W (1993) Ultimate causes of vertical migration of zooplankton: new evidence for the predator-avoidance hypothesis. Ergeb Limol 39:79-88

Mackas DL, Tsuda A (1999) Mesozooplankton in the eastern and western subarctic Pacific: community structure, seasonal life histories, and inerannual variability. Prog Oceanogr 43:335-363

Miller CB, Clemons MJ (1988) Revised life history analysis for large grazing copepods in the subarctic Pacific Ocean. Prog Oceanogr 20:293-313

Miller CB, Terazaki M (1989) The life histories of Neocalanus flemingeri and Neocalanus plumchrus in the Sea of Japan. Bull Plankton Soc Jap 36:27-41

Miller CB, Frost BW, Batchelder HP, Clemons MJ, Conway RE (1984) Life histories of large, grazing copepods in the subarctic ocean gyre: Neocalanus plumchrus, Neocalanus cristatus and Eucalanus bungii in the Northeast Pacific. Prog Oceanogr 13: 201-243

Minoda T (1971) Pelagic copepoda in the Bering Sea and the north-western north Pacific with special reference to their vertical distribution. Mem Fac Fish Hokkaido Univ 18: $1-74$

Moku M, Kawaguchi K, Watanabe H, Ohno A (2000) Feeding habits of three dominant myctophid fishes, Diaphus theta, Stenobrachius leucopsarus and S. nannochir, in the subarctic and transitional waters of the western North Pacific. Mar Ecol Prog Ser 207:129-140

Morioka Y (1976) Vertical invasion of boreal calanoid copepods into the shallow warm stratum. Bull Jap Sea Reg Fish Res Lab 26:41-56

Motoda S (1957) North Pacific standard net. Inf Bull Planktol Jpn 4:13-15 (in Japanese with English abstract)

Nakatani T (1995) Monthly changes in density and size structure of copepod nauplii as the primary food for fish larvae in winter in Funka Bay and surrounding vicinity in Hokkaido. Fish Sci 61:382-386

Nemoto T (1963) Some aspects of the distribution of Calanus cristatus and $C$. plumchrus in the Bering Sea and its neighbouring waters, with reference to the feeding of baleen whales. Sci Rep Whales Res Inst Tokyo 17:157-170

Odate K (1994) Zooplankton biomass and its long-term variation in the western North Pacific Ocean, Tohoku Sea area, Japan. Bull Tohoku Natl Fish Res Inst 56:115-173

Ohman MD, Drits AV, Clarke ME, Plourde S (1998) Differential dormancy of co-occurring copepods. Deep-Sea Res II 45:1709-1740

Ohtani K (1971) Studies on the change of the hydrographic conditions in the Funka Bay. II. Characteristics of the waters occupying the Funka Bay. Bull Fac Fish Hokkaido Univ 22:58-66

Ozaki K, Takeuchi T, Shiga N, Mito K (2001) Winter zooplankton biomass and population structure of calanoid copepods in the Bering Sea basin. Plankton Biol Ecol 48:46-51

Padmavati G, Ikeda T (2002) Development of Metridia pacifica (Crustacea: Copepoda) reared at different temperatures in the laboratory. Plankton Biol Ecol 49:93-96

Pinchuk AI, Paul AJ (1998) Growth of Metridia pacifica (Copepoda: Calanoida) nauplii in the laboratory. Plankton Biol Ecol 45:195-201

Pinchuk AI, Paul AJ (2000) Zooplankton of the Okhotsk Sea: a review of Russian studies. University of Alaska Sea Grant College Program, Fairbanks, AK

Planque B, Hays GC, Ibanez F, Gamble JC (1997) Large-scale spatial variations in the seasonal abundance of Calanus finmarchicus. Deep-Sea Res 44:315-326
Raymont JEG (1983) Plankton and productivity in the oceans. zooplankton, 2nd edn. Pergamon Press, Oxford

Reid JL (1973) North Pacific Ocean waters in winter. The Johns Hopkins Oceanographic Studies No. 5. The Johns Hopkins Press, Baltimore, MD, p 1-96

Romano P, Feletti M, Mariottini GL, Carli A (1999) Ecological and nutritional implications of the mandibular structure in the Antarctic calanoid copepod Metridia gerlachei Giesbrecht, 1902: an ultrastructural study. Polar Biol 22:7-12

Saito H, Kotani Y (2000) Lipids of four boreal species of calanoid copepods: origin of monene fats of marine animals at higher trophic levels in the grazing food chain in the subarctic ocean ecosystem. Mar Chem 71:69-82

Saitoh S, Kishino M, Kiyohuji H, Taguchi S, Takahashi M (1996) Seasonal variability of phytoplankton pigment concentration in the Okhotsk Sea. Bull Remote Sens Soc Jap 16:86-92

Shebanova MA (1994) Distribution of Metridia pacifica copepods in winter in the epipelagic layer of the Okhotsk Sea. Biol Morya 20:426-429

Shinada A, Ikeda T, Ban S, Tsuda A (2001) Seasonal dynamics of plankton food chain in the Oyashio region, western subarctic Pacific. J Plankton Res 23:1237-1247

Shoden S (2000) The biological and ecological studies on the planktonic copepod Eucalanus bungii (Giesbrecht) in the Oyashio region. MSc thesis, Graduate School of Fisheries Science, Hokkaido University

Takahashi K (1986) Seasonal fluxes of pelagic diatoms in the subarctic Pacific, 1982-1983. Deep-Sea Res 33:1225-1251

Takeuchi I (1972) Food animals collected from the stomachs of three salmonid fishes (Oncorhynchus) and their distribution in the natural environments in the northern North Pacific. Bull Hokkaido Reg Fish Res Lab 38:1-119 (in Japanese with English abstract)

Tande KS, Grønvik S (1983) Ecological investigations on the zooplankton community of Balsfjorden, northern Norway: sex ratio and gonal maturation cycle in the copepod Metridia longa (Lubbock). J Exp Mar Biol Ecol 71:43-54

Terazaki M (1998) Life history, distribution, seasonal variability and feeding of the pelagic chaetognath Sagitta elegans in the Subarctic Pacific: a review. Plankton Biol Ecol 45:1-17

Terazaki M, Tomatsu C (1997) A vertical multiple opening and closing plankton sampler. J Adv Mar Sci Technol Soc $3: 127-132$

Tsuda A, Saito H, Kasai H (1999) Life histories of Neocalanus flemingeri and Neocalanus plumchrus (Calanoida: Copepoda) in the western subarctic Pacific. Mar Biol 135: 533-544

Uchikawa K, Yamamura O, Sakurai Y (2001) Feeding habits of the mesopleagic fish Gonostoma gracile in the northwestern North Pacific. J Oceanogr Soc Jap 57:509-517

Vidal J (1980) Physioecology of zooplankton. IV. Effects of phytoplankton concentration, temperature, and body size on the net production efficiency of Calanus pacificus. Mar Biol 56:203-211

Vinogradov ME (1970) Vertical distribution of the oceanic zooplankton. Israel Program for Scientific Translations, Jerusalem

Vinogradov ME, Arashkevich EG (1969) Vertical distribution of interzonal copepod filter feeders and their role in communities at different depths in the north-western Pacific. Okeanologia 9:399-409

Ward P, Atkinson A, Schnack-Schiel SB, Murray AWA (1997) Regional differences in the life cycle of Rhincalanus gigas (Copepoda: Calanoida) in the Antarctic sector of the Southern Ocean: re-examination of existing data (1928 to 
1993). Mar Ecol Prog Ser 157:261-275

Welschmeyer NA, Strom S, Goericke R, Ditullio G, Belvin M, Petersen W (1993) Primary production in the subarctic Pacific Ocean: project SUPER. Prog Oceanogr 32:101-135 Yamaguchi A, Ikeda T, Shiga N (1998) Population structure and life cycle of Pseudocalanus minutus and Pseudo-

Editorial responsibility: Michael Landry (Contributing Editor), La Jolla, California, USA calanus newmani (Copepoda: Calanoida) in Toyama Bay, southern Japan Sea. Plankton Biol Ecol 45:183-193

Yamaguchi A, Watanabe $Y$, Ishida $H$, Harimoto $T$ and 5 others (2002) Community and trophic structures of pelagic copepods down to greater depths in the western subarctic Pacific (WEST-COSMIC). Deep-Sea Res I 49:1007-1025

Submitted: October 7, 2002; Accepted: November 13, 2003 Proofs received from author(s): March 12, 2004 